University of Louisville

ThinkIR: The University of Louisville's Institutional Repository

8-2014

\title{
An investigation of heat transfer enhancement in nanofluids containing core and shell nanoparticles.
}

Cory Adam Milligan

University of Louisville

Follow this and additional works at: https://ir.library.louisville.edu/etd

Part of the Chemical Engineering Commons

\section{Recommended Citation}

Milligan, Cory Adam, "An investigation of heat transfer enhancement in nanofluids containing core and shell nanoparticles." (2014). Electronic Theses and Dissertations. Paper 983.

https://doi.org/10.18297/etd/983

This Master's Thesis is brought to you for free and open access by ThinkIR: The University of Louisville's Institutional Repository. It has been accepted for inclusion in Electronic Theses and Dissertations by an authorized administrator of ThinkIR: The University of Louisville's Institutional Repository. This title appears here courtesy of the author, who has retained all other copyrights. For more information, please contact thinkir@louisville.edu. 


\author{
By \\ Cory Adam Milligan \\ B.S., University of Louisville, 2014

\begin{abstract}
A Thesis
Submitted to the Faculty of the

University of Louisville

J.B. Speed School of Engineering

As Partial Fulfillment of the Requirements

For the Professional Degree
\end{abstract}

\title{
MASTER OF ENGINEERING
}

Department of Chemical Engineering

August 2014 


\title{
AN INVESTIGATION OF HEAT TRANSFER ENHANCEMENT IN NANOFLUIDS CONTAINING CORE \& SHELL NANOPARTICLES
}

\author{
Submitted by: \\ Cory Adam Milligan \\ A Thesis Approved On \\ (Date)
}

By the Following Reading and Examination Committee:

\begin{tabular}{c}
\hline Gerald Willing, Thesis Director \\
\hline James Watters \\
\hline
\end{tabular}

Cindy Harnett 


\section{ACKNOWLEDGEMENTS}

I would like to thank my thesis advisor, Dr. Willing, for his guidance throughout my entire education and my research. His advice has allowed me to gain important life lessons that will no doubt help me in my future endeavors.

I would like to thank Dr. Watters and Dr. Cindy Harnett for taking time out of their busy schedule to sit on my thesis committee.

I would like to thank all of my friends and family for their continued support throughout all of education. Without them I'm not sure if I would have made it. 


\begin{abstract}
The purpose of this research is to determine the differences in heat transfer enhancement of poly alpha olefin oil after the addition of two types of carbon coated nanoparticles, specifically carbon coated cobalt and carbon coated copper nanoparticles. The carbon shell allows for the nanoparticles to be homogenously dispersed in the oil and remain stable throughout the experimental procedure. The nanofluids were prepared in concentrations of $0.5,1.0$, and $1.5 \mathrm{wt} \%$.
\end{abstract}

A constant surface heat flux testing rig is used to determine the heat transfer coefficients of the base fluids and the nanofluids. Inlet temperatures to the heat transfer section of the rig and flow rate of the fluid are varied to allow analysis of the impact of fluid temperature and Reynolds number. Testing occurred at temperatures of 50,65 , and $90{ }^{\circ} \mathrm{C}$ and fluid flow rates of 10 to $100 \mathrm{~mL} / \mathrm{s}$.

The carbon coated copper nanoparticles showed the largest heat transfer enhancement at a fluid temperature of $65^{\circ} \mathrm{C}$ and at a loading concentration of $1.0 \mathrm{wt} \%$. In general heat transfer enhancement decreased as both particle concentration and fluid temperature increased. The carbon coated cobalt nanoparticles exhibited the largest heat transfer enhancement at a fluid temperature of $90{ }^{\circ} \mathrm{C}$ and a particle concentration of $1.5 \mathrm{wt} \%$. Heat transfer enhancement generally increased as both temperature and particle concentration increased. Overall heat transfer enhancement by the carbon coated copper nanoparticles was larger than the enhancement provided by the carbon coated cobalt 
nanoparticles at the same flow rate, temperature, and concentration. This is attributed to the higher thermal conductivity of copper metal. 


\section{TABLE OF CONTENTS}

APPROVAL PAGE




\section{NOMENCLATURE}

$\mathrm{C}_{\mathrm{p}}=$ heat capacity, $\mathrm{J} /\left(\mathrm{kg}{ }^{*} \mathrm{~K}\right)$

$C_{p, f}=$ heat capacity of base fluid, $J /(k g * K)$

$\mathrm{C}_{\mathrm{p}, \mathrm{n}}=$ heat capacity of nanoparticle, $\mathrm{J} /\left(\mathrm{kg}^{*} \mathrm{~K}\right)$

$\mathrm{C}_{\mathrm{p}, \mathrm{nf}}=$ heat capacity of nanofluid, $\mathrm{J} /(\mathrm{kg} * \mathrm{~K})$

$d=$ diameter of heat transfer section, $m$

$h=$ heat transfer coefficient, $W /\left(m^{2 *} K\right)$

$\mathrm{L}=$ length of heat transfer section, $\mathrm{m}$

$\dot{m}=$ mass flow rate of liquid, $\mathrm{g} / \mathrm{s}$

$\mathrm{Q}=$ heat transfer rate per unit area, $\mathrm{J} /\left(\mathrm{m}^{2 *} \mathrm{~s}\right)$

$T_{f}=$ temperature of the fluid, ${ }^{\circ} \mathrm{C}$

$\widetilde{T_{f}}=$ average temperature of the fluid through heat transfer section, ${ }^{\circ} \mathrm{C}$

$\mathrm{T}_{\mathrm{i}}=$ temperature of fluid entering heat transfer section, ${ }^{\circ} \mathrm{C}$

$\mathrm{T}_{\mathrm{o}}=$ temperature of fluid leaving heat transfer section, ${ }^{\circ} \mathrm{C}$

$\mathrm{T}_{\mathrm{w}}=$ temperature of the wall, ${ }^{\circ} \mathrm{C}$

$\widetilde{T_{W}}=$ average temperature of the wall of heat transfer section, ${ }^{\circ} \mathrm{C}$

$\dot{V}=$ volumetric flow rate, $\mathrm{m}^{3} / \mathrm{s}$

$\rho=$ density, $\mathrm{kg} / \mathrm{m}^{3}$

$\rho_{\mathrm{f}}=$ density of base fluid, $\mathrm{kg} / \mathrm{m}^{3}$

$\rho_{\mathrm{n}}=$ density of nanoparticle, $\mathrm{kg} / \mathrm{m}^{3}$

$\varnothing=$ nanoparticle volume concentration 


\section{LIST OF TABLES}

Table 1 - Spreadsheet used to calculate heat transfer coefficient of PAO base

fluid used for carbon coated copper nanofluid dispersions at $40{ }^{\circ} \mathrm{C}$

Table 2 - Viscosity results for cobalt base fluid at various temperatures and shear rates 


\section{LIST OF FIGURES}

Figure 1 - Fisher Scientific Model 500 Ultrasonic Dismembrator setup 9

Figure 2 - Brookfield Model DV-II Programable Rheometer setup 10

Figure 3 - TA Instruments Q20 Differential Scanning Calorimeter 11

Figure 4 - In house build heat transfer rig $\quad 12$

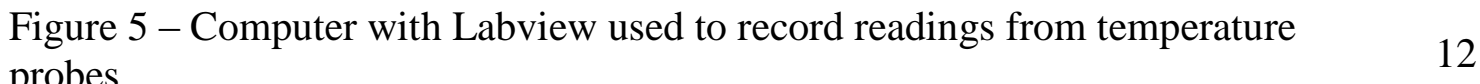

Figure 6 - Viscosity of carbon coated cobalt nanofluid dispersed in PAO base fluid at a loading concentration of $0.5 \mathrm{wt} \%$ as a function of temperature

Figure 7 - Viscosities of carbon coated copper nanofluids dispersed in PAO at different loading concentrations and temperatures

Figure 8 - Viscosities of carbon coated cobalt nanofluids dispersed in PAO at different loading concentrations and temperatures

Figure 9 - Heat capacities of carbon coated copper nanofluids dispersed in PAO at different loading concentrations and temperatures

Figure 10 - Heat capacities of carbon coated cobalt nanofluids dispersed in PAO at different loading concentrations and temperatures

Figure 11 - Theoretical heat capacities of carbon coated copper nanofluids dispersed in PAO at different loading concentrations and temperatures

Figure 12 - Theoretical heat capacities of carbon coated cobalt nanofluids dispersed in PAO at different loading concentrations and temperatures

Figure 13 - Heat transfer coefficients of carbon coated copper nanofluids dispersed in PAO at different loading concentrations as a function of Reynolds Number at $50{ }^{\circ} \mathrm{C}$

Figure 14 - Heat transfer coefficients of carbon coated copper nanofluids dispersed in PAO at different loading concentrations as a function of Reynolds Number at $65{ }^{\circ} \mathrm{C}$

Figure 15 - Heat transfer coefficients of carbon coated copper nanofluids dispersed in PAO at different loading concentrations as a function of Reynolds Number at $90{ }^{\circ} \mathrm{C}$ 
Figure 16 - Heat transfer enhancement of carbon coated copper nanofluids dispersed in PAO at different loading concentrations as a function of Reynolds Number at $50{ }^{\circ} \mathrm{C}$

Figure 17 - Heat transfer enhancement of carbon coated copper nanofluids dispersed in PAO at different loading concentrations as a function of Reynolds Number at $65{ }^{\circ} \mathrm{C}$

Figure 18 - Heat transfer enhancement of carbon coated copper nanofluids dispersed in PAO at different loading concentrations as a function of Reynolds Number at $90{ }^{\circ} \mathrm{C}$

Figure 19 - Heat transfer coefficients of carbon coated cobalt nanofluids dispersed in PAO at different loading concentrations as a function of Reynolds Number at $50{ }^{\circ} \mathrm{C}$

Figure 20 - Heat transfer coefficients of carbon coated cobalt nanofluids dispersed in PAO at different loading concentrations as a function of Reynolds Number at $65^{\circ} \mathrm{C}$

Figure 21 - Heat transfer coefficients of carbon coated cobalt nanofluids dispersed in PAO at different loading concentrations as a function of Reynolds Number at $90{ }^{\circ} \mathrm{C}$

Figure 22 - Heat transfer enhancement of carbon coated cobalt nanofluids dispersed in PAO at different loading concentrations as a function of Reynolds Number at $50{ }^{\circ} \mathrm{C}$

Figure 23 - Heat transfer enhancement of carbon coated cobalt nanofluids dispersed in PAO at different loading concentrations as a function of Reynolds Number at $65{ }^{\circ} \mathrm{C}$

Figure 24 - Heat transfer enhancement of carbon coated cobalt nanofluids dispersed in $\mathrm{PAO}$ at different loading concentrations as a function of Reynolds Number at $90{ }^{\circ} \mathrm{C}$

Figure 25 - Viscosity of PAO used as base fluid for carbon coated cobalt nanofluid dispersions as a function of temperature

Figure 26 - Viscosity of carbon coated cobalt nanofluid dispersed in PAO base fluid at a loading concentration of $1.0 \mathrm{wt} \%$ as a function of temperature

Figure 27 - Viscosity of carbon coated cobalt nanofluid dispersed in PAO base fluid at a loading concentration of $1.5 \mathrm{wt} \%$ as a function of temperature 
Figure 28 - Viscosity of PAO used as base fluid for carbon coated copper nanofluid dispersions as a function of temperature

Figure 29 - Viscosity of carbon coated copper nanofluid dispersed in PAO base fluid at a loading concentration of $0.5 \mathrm{wt} \%$ as a function of temperature

Figure 30 - Viscosity of carbon coated copper nanofluid dispersed in PAO base fluid at a loading concentration of $1.0 \mathrm{wt} \%$ as a function of temperature

Figure 31 - Viscosity of carbon coated copper nanofluid dispersed in PAO base fluid at a loading concentration of $1.5 \mathrm{wt} \%$ as a function of temperature

Figure 32 - Heat transfer enhancement of carbon coated copper nanofluids dispersed in PAO at different loading concentrations as a function of Flow Rate at $50{ }^{\circ} \mathrm{C}$

Figure 33 - Heat transfer enhancement of carbon coated copper nanofluids dispersed in PAO at different loading concentrations as a function of Flow Rate at $65{ }^{\circ} \mathrm{C}$

Figure 34 - Heat transfer enhancement of carbon coated copper nanofluids dispersed in PAO at different loading concentrations as a function of Flow Rate at $90{ }^{\circ} \mathrm{C}$

Figure 35 - Heat transfer enhancement of carbon coated cobalt nanofluids dispersed in PAO at different loading concentrations as a function of Flow Rate at $50{ }^{\circ} \mathrm{C}$

Figure 36 - Heat transfer enhancement of carbon coated cobalt nanofluids dispersed in PAO at different loading concentrations as a function of Flow Rate at $65^{\circ} \mathrm{C}$

Figure 37 - Heat transfer enhancement of carbon coated cobalt nanofluids dispersed in PAO at different loading concentrations as a function of Flow Rate 54 at $90{ }^{\circ} \mathrm{C}$ 


\section{INTRODUCTION}

Heat transfer is one of the most fundamental and essential chemical engineering concepts. Heat transfer is used in essentially every chemical industry in some form. Typically heat must either be removed or added from the system by using heat transfer fluids. The current heat transfer fluids being utilized in industry however, have poor thermal properties when compared to other materials. For instance solid and liquid metals have thermal properties that are orders of magnitude better than these traditional heat transfer fluids. [1] In 1873 Maxwell proposed a mechanism to improve the thermal properties of a fluid by adding micron-sized particles to the fluid. [2] The addition of the solid particles did in fact increase the thermal properties of these fluids; however, several negative effects were also added to the fluid. These issues of rapid sedimentation, erosion, clogging, and high-pressure drop negated the heat transfer benefits of the fluid, making it impractical to use in industry.

\section{Nanofluids}

The next major advancement in the improvement of thermal properties of heat transfer fluids was made in 1995 by Choi, a researcher at Argonne National Labs. Choi discovered that the additional of a small amount of metal nanoparticles to a fluid (Nanofluid) would increase the fluid's heat transfer properties by a significant amount. [1] This development helped to alleviate many of the issues that were encountered with the micron-sized particles suspended in a fluid. Due to the order of magnitude size reduction of the particles they also exhibit much better colloidal stability. 


\section{Creating a Stable Suspension}

\section{Surfactant}

In order for the fluids to maintain a stable suspension, the particles cannot be allowed to agglomerate. The primary methodology for hindering this is by the application of a surfactant. Surfactants are typically organic compounds that are amphiphilic, meaning that they contain both a hydrophobic tail and a hydrophilic head. When the surfactant is added to the nanoparticle suspension the molecules preferentially align and coat the nanoparticles. The hydrophilic tail remains in favorable contact with the oil phase and the hydrophobic head creates favorable contact with the nanoparticle. This arrangement causes a creation of a buffer region around the nanoparticles that negates the van der Waals attraction forces that would typically be present between the particles, thus creating a stable suspension.

The hydrophobic and hydrophilic nature of these chemicals do not provide enough attractive forces on their own to ensure that they stay attached to the surface of the nanoparticle. In order for the surfactant to be bound to the nanoparticle a second force must be present. This brings in two major classifications that differentiate surfactants, chemisorbed and physisorbed.

A chemisorbed surfactant is one that adheres to the surface of a nanoparticle by chemically reacting with its surface. An example would be 1-hexadecanethiol as the surfactant in a system with copper nanoparticles. A physisorbed surfactant is a chemical that has a relatively strong van der Waals attraction force with the nanoparticle. Due to 
the differences in the adsorption mechanisms, chemisorbed surfactants typically form a more stable suspension. In a high temperature system physisorbed surfactants are even less ideal due to the high kinetic energy in the system.

Several different surfactants have been utilized to prepare nanofluids. Xuan and Li used oleic acid to stabilize copper nanoparticles in transformer oil. [3] In their experiments they determined that creating a suspension that was stable for a week required an amount of oleic acid equal to $22 \mathrm{wt} \%$ of the nanoparticles. Xuan and Li also used laurate salt as a surfactant in order to create a suspension of copper nanoparticles in water. At a $9 \mathrm{wt} \%$ of surfactant in relation to nanoparticle, a suspension was created that remained stable for 30 hours.

The addition of a surfactant makes the system more stable; however, it also impacts the heat transfer improvements of the nanofluid. Li et al. showed that the concentration of the surfactant added to the nanofluid greatly influences the thermal conductivity enhancements. [4] The nanofluid system studied in their report was copper nanoparticles in a water base fluid with sodium dodecylbenzenesulfonate (SDBS) as the surfactant. Starting from a low overall mass fraction of SDBS $(0.2 \mathrm{wt} \%)$ they noticed a gradual decrease in the thermal conductivity enhancement as surfactant concentration increased to $0.1 \mathrm{wt} \%$. As the concentration of surfactant is increased further to $0.12 \mathrm{wt} \%$ they report a large decrease in thermal conductive enhancement. 


\section{Direct Carbon Layer}

An alternative method to making nanoparticles readily stable in a fluid is by directly synthesizing the nanoparticles with a carbon shell. The ability to encapsulate metals in carbon nanoparticles was discovered in 1993 by Ruoff et al. [5] In their experiment Ruoff et al. were able to synthesize lanthanum carbide $\left(\mathrm{LaC}_{2}\right)$ nanoparticles that were encapsulated in nanoscale polyhedral carbon particles. Upon analysis of the EDS spectrum it was noted that carbon and La were present in the crystals and that no oxygen was present. The group also allowed the particles to sit in contact with air for several days and performed a chemical analysis of the particles again. This analysis showed that even after prolonged contact with oxygen, the carbon shell still prevented oxidation of the La crystals. This experiment created a new core and shell class of nanoparticle, where a pure metal nanocrystal could be synthesized and made immune to oxidative effects allowing for utilization of their unique properties.

In addition to the chemical and oxidative protection provided, the carbon shell also provides an enhancement in the colloidal stability of these nanoparticles, making them ideal candidates when creating nanofluids. Due to the fact that creating transition metals encapsulated in carbon is a fairly new achievement there are few papers studying the colloidal stability of these nanoparticles. However, in a recently published paper by Uhm et al. the dispersion stabilities of $\mathrm{Ag}$ and $\mathrm{Cu}$ nanoparticles were studied. [6] They created a stable dispersion of $\mathrm{Ag}$ nanoparticle in a polyethylene glycol base fluid, and a stable dispersion of $\mathrm{Cu}$ nanoparticles in ethylene glycol and polyethylene glycol. Flocculation 
of the nanoparticles did not occur due to the mediation of the van der Waals attraction forces by the carbon coating.

\section{Nanofluid Preparation}

There have been several proposed methods to create nanofluid suspensions. These methods are generally divided into two main divisions, one-step and two-step preparation.

\section{One-Step Preparation}

In the one-step preparation the nanoparticles are synthesized and directly dispersed into the base fluid. This can be done by either physical vapor deposition or a liquid chemical method. In physical vapor deposition a solid metal is vaporized and the metallic vapor is then condensed into a liquid with a low vapor pressure. This method of synthesis has been successfully completed by Eastman et. al. for creating a copper in ethylene glycol dispersion. [7] In a liquid chemical method a chemical reaction is employed to directly synthesize nanoparticles in the base fluid. Liu et al successfully created copper nanoparticles in a water base fluid using this method. [8] In their research copper acetate was added to deionized water and thoroughly mixed. Hydrazine was then added to facilitate the reduction reaction to produce the copper nanoparticles. The general benefit to producing nanofluids with the one-step preparation method is that agglomeration of the dry nanoparticles is avoided. 


\section{Two- Step Preparation}

In the two step methods a previously prepared nanoparticle is physically dispersed into a base fluid. There are several different ways that nanofluids can be prepared using a twostep method. The most popular of these methods uses a stirrer, ultrasonic bath, ultrasonic disruptor, or a high-pressure homogenizer. The purpose of the mixing equipment is to break the up any aggregation that has occurred in the nanoparticles. These four methods have been thoroughly tested by Hwang et al. to determine the ideal mixing method for both carbon black and gold nanoparticles. [9]

Hwang's tests utilized a four blade stirrer that rotated at a speed of $1500 \mathrm{rpm}$ for 2 hours. For sonication they utilized both an ultrasonic bath and an ultrasonic disrupter with an operating time of an hour for both. In the ultrasonic bath, waves generated by the equipment are transferred to the test fluid indirectly through water. The ultrasonic disrupter creates the ultrasonic waves directly into the test fluid from its submerged tip. The final testing equipment was the high pressure homogenizer that works by increasing fluid velocity to an extremely high value and spraying it into an interaction chamber. In their preparation they processed the fluid three times at pressures of $18,000 \mathrm{psi}$.

They found that the high-pressure homogenizer produced the most stable nanofluid and reversed the highest amount of aggregation that had occurred in the dry nanoparticles. The ultrasonic disrupter produced fluids of slightly higher particle diameters and slightly worse dispersion stability than that of the high-pressure homogenizer. Both the stirrer and 
the ultrasonic bath resulted in far worse particle size and much lower dispersion stability compared to the other two methods.

\section{Previous Research on Oil Based Nanofluids at Low Volume Fractions}

There has not been extensive research done on heat transfer enhancement of nanofluids at low volume concentrations $<0.25$ vol\% with motor oil as the base fluid. Liu has published a preliminary investigation on the effect of particle size on the heat transfer enhancement in this concentration regime. [10] A decrease in particle size caused an increase in the heat transfer enhancement of the fluid. This enhancement is attributed to the increase of surface area with respect to volume when particle diameter decreases, allowing for more surface for heat transfer to occur.

Another report, by Rucker, analyzed the differences in heat transfer enhancement of copper nanoparticles against copper oxide nanoparticles. [11] In this research it was found that at low concentrations, the addition of nanoparticles caused a decrease in heat transfer coefficient, not an increase. However, copper nanoparticles did not decrease the heat transfer coefficient as severely as copper oxide nanoparticles. This was attributed to the fact that the thermal conductivity of the copper nanoparticle is higher than that of copper oxide.

Another factor studied by Rucker was the effect of surfactant on the heat transfer enhancement. Both physisorbed, CTAB, and chemisorbed, 1-hexadecanethiol, surfactants were studied with the copper nanoparticles. While there was no clear trend present in regards to the heat transfer enhancement when using the different surfactants, there was a 
difference in relation to nanoparticle stability. Sample preparation took several more hours of sonication to generate a stable suspension with CTAB surfactant when compared to sample prepared with 1-hexandecanethiol surfactant, leading to the conclusion that chemisorbed surfactants should be utilized when preparing oil based nanofluids.

The present research has two main objectives. The first one is to create stable suspensions of carbon coated metal nanoparticles in poly-alpha-olefin motor oil. Two different metal cores are used in the research, cobalt and copper. The second objective is to investigate the heat transfer enhancements caused by the addition of these nanoparticles at low volume fractions. Several system properties will be varied in order to allow for robust analysis of these enhancements including flow properties, temperature, and nanoparticle loading concentration. As a result of adding nanoparticles to the fluid, other properties, such as specific heat and viscosity, also change and can affect this analysis. These properties will also be measured to determine their effect on results. 


\section{INSTRUMENTATION AND EQUIPMENT}

A Fisher Scientific Model 500 Ultrasonic Dismembrator was used to disperse the nanoparticles in the base fluid. The sonicator operates on a feed of A/C power, which it converts to a $20 \mathrm{kHz}$ signal. Piezoelectric crystals of lead zirconate titanate convert the electric feed to a mechanical vibration. The mechanical vibration is transmitted down the length of the horn causing the tip to expand and contract. The expansion and contraction of the tip causes cavitation to occur in the fluid, the generation and implosion of thousands of micro-bubbles, processing the sample. The amount of fluid able to be processed by the sonicator depends on the tip size used. For processing large batches, up to $500 \mathrm{~mL}$, the standard $1 / 2$ " tip is used. For processing sample batches, $5-50 \mathrm{~mL}$, the $1 / 4$ " micro-tip adapter is used.

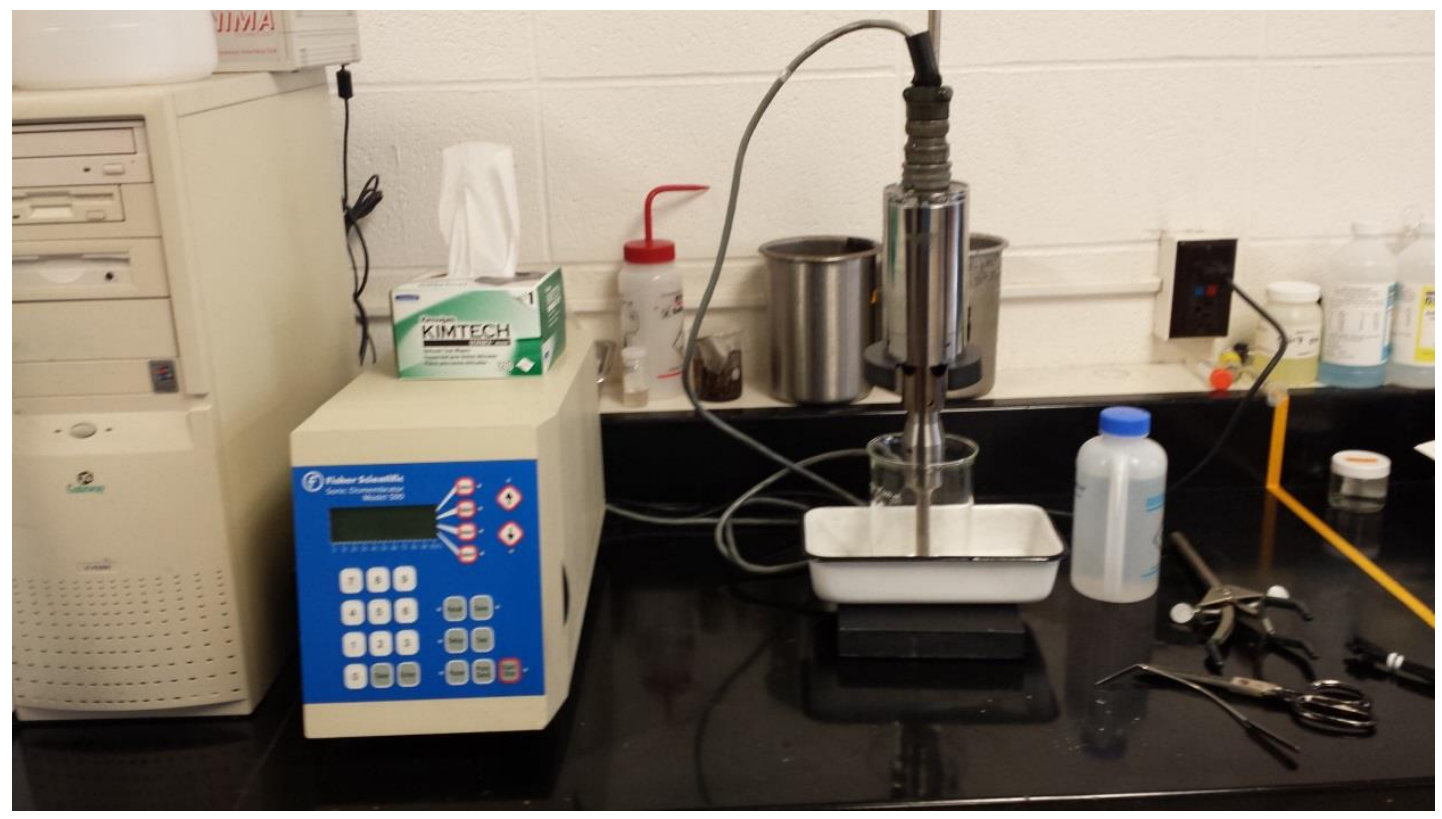

Figure 1 - Fisher Scientific Model 500 Ultrasonic Dismembrator setup 
The viscosity of each fluid was measured using a Brookfield Model DV-II Programmable Rheometer. This is a cone and plate rheometer that measures shear stress and viscosity at variable shear rates. A cone and plate rheometer operates by placing a sample of fluid between a flat plate and a cone with a very small angle. The cone then rotates at a specified speed and the torque required to maintain the speed is measured. The combination of the torque and rotation speed can then be used to calculate the viscosity of the fluid. The Brookfield Rheometer used allows for a rotation speed of 0-250 RPM to be selected. Different cones may be used depending on the physical properties of the fluid being tested. For the present measurements the CP-40 cone was used. The CP-40 cone processes a sample volume of $0.5 \mathrm{~mL}$ and has a cone angle of $0.8^{\circ}$. This cone allows for the measurement of liquids in the viscosity range of 1-3000 centipoise. An external water bath is connected to the port of the sample cup to maintain the temperature of the sample with a (+/-) $0.1{ }^{\circ} \mathrm{C}$ precision.

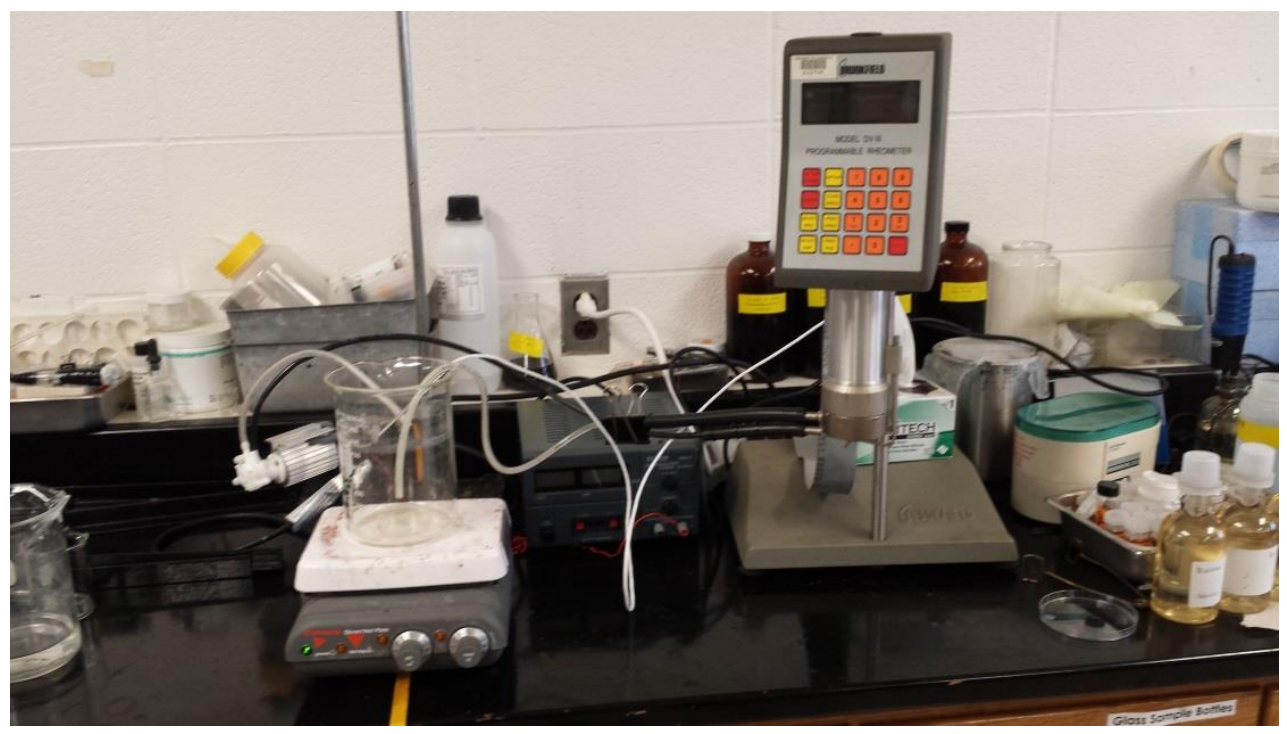

Figure 2 - Brookfield Model DV-II Programmable Rheometer setup 
A TA Instruments Q20 Differential Scanning Calorimeter (DSC) was used to measure the heat capacity of the samples. A DSC operates by comparing the temperature change between the sample, with an unknown heat capacity, and an empty pan, with a known heat capacity. As heat is applied to both pans the temperature of the samples also change, representing a change in internal energy. This change in internal energy allows for the determination of the heat capacity of the sample. A DSC must be calibrated by analyzing a sample with well-known thermal properties. In this case, the DSC was calibrated using sapphire in reference to an empty pan.

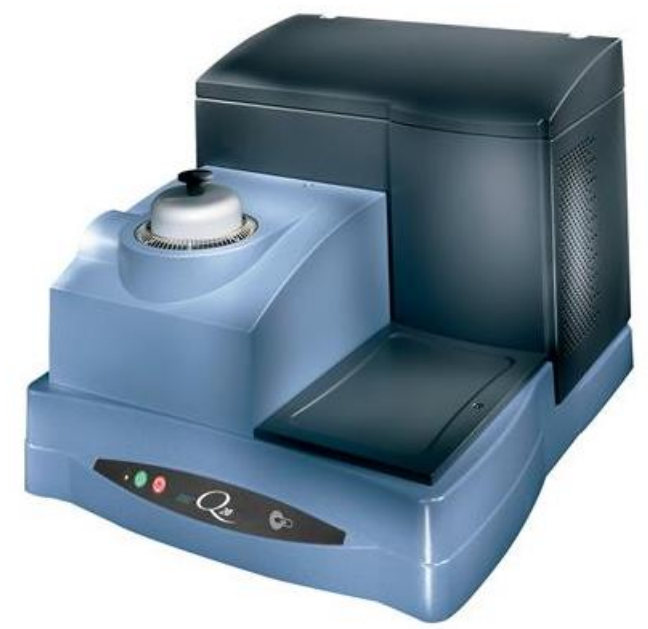

Figure 3 - TA Instruments Q20 Differential Scanning Calorimeter

A built in-house heat transfer rig was used to measure the heat transfer coefficient of the nanofluid. The heat transfer rig consists of a fluid reservoir, centrifugal pump, flow meter, water bath, and a data acquisition section. The data acquisition section consists of insulated copper tubing covered with heat tracing. There are eight thermocouples along 
the section that allows for real time temperature measurements to be taken in Labview. The system can facilitate flow rates from $0.1 \mathrm{GPM}$ to $4.8 \mathrm{GPM}$.

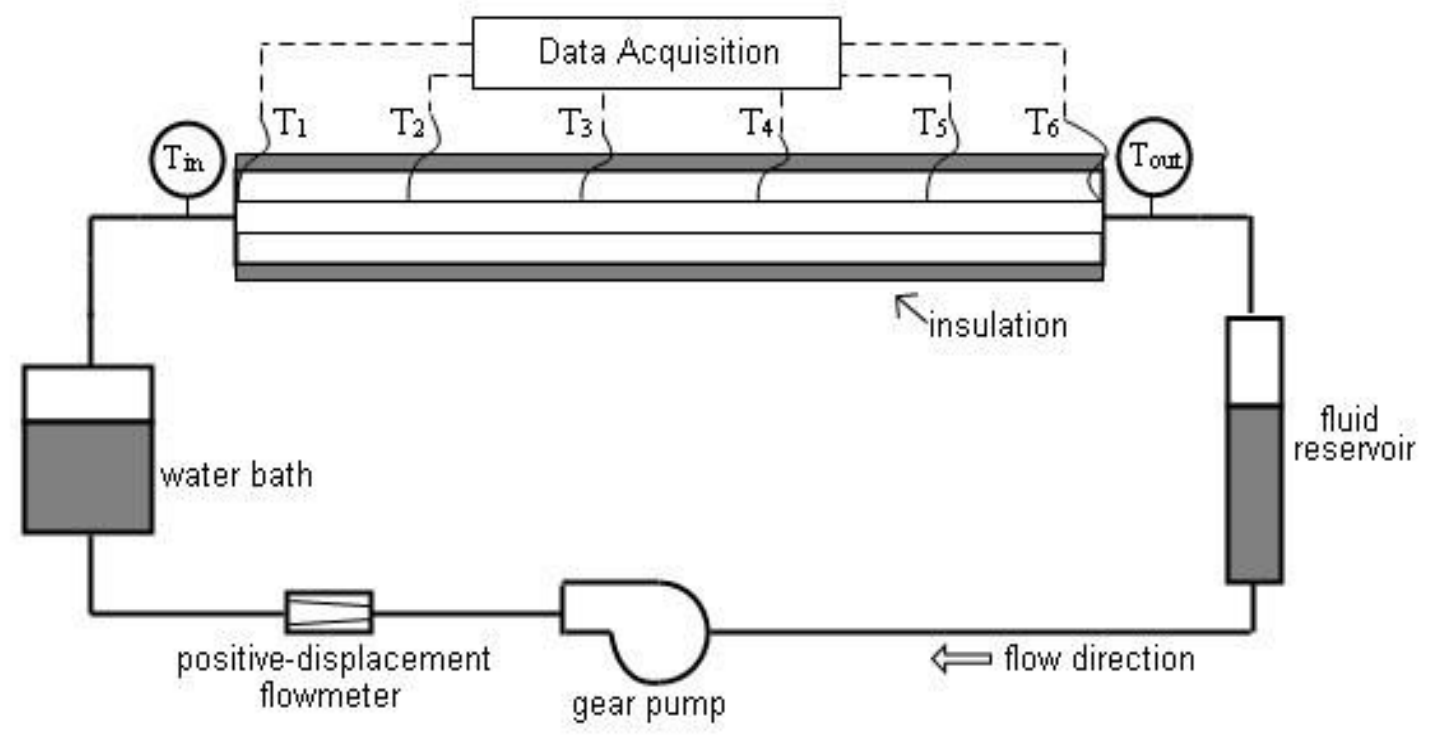

Figure 4 - Schematic of In-house built heat transfer rig

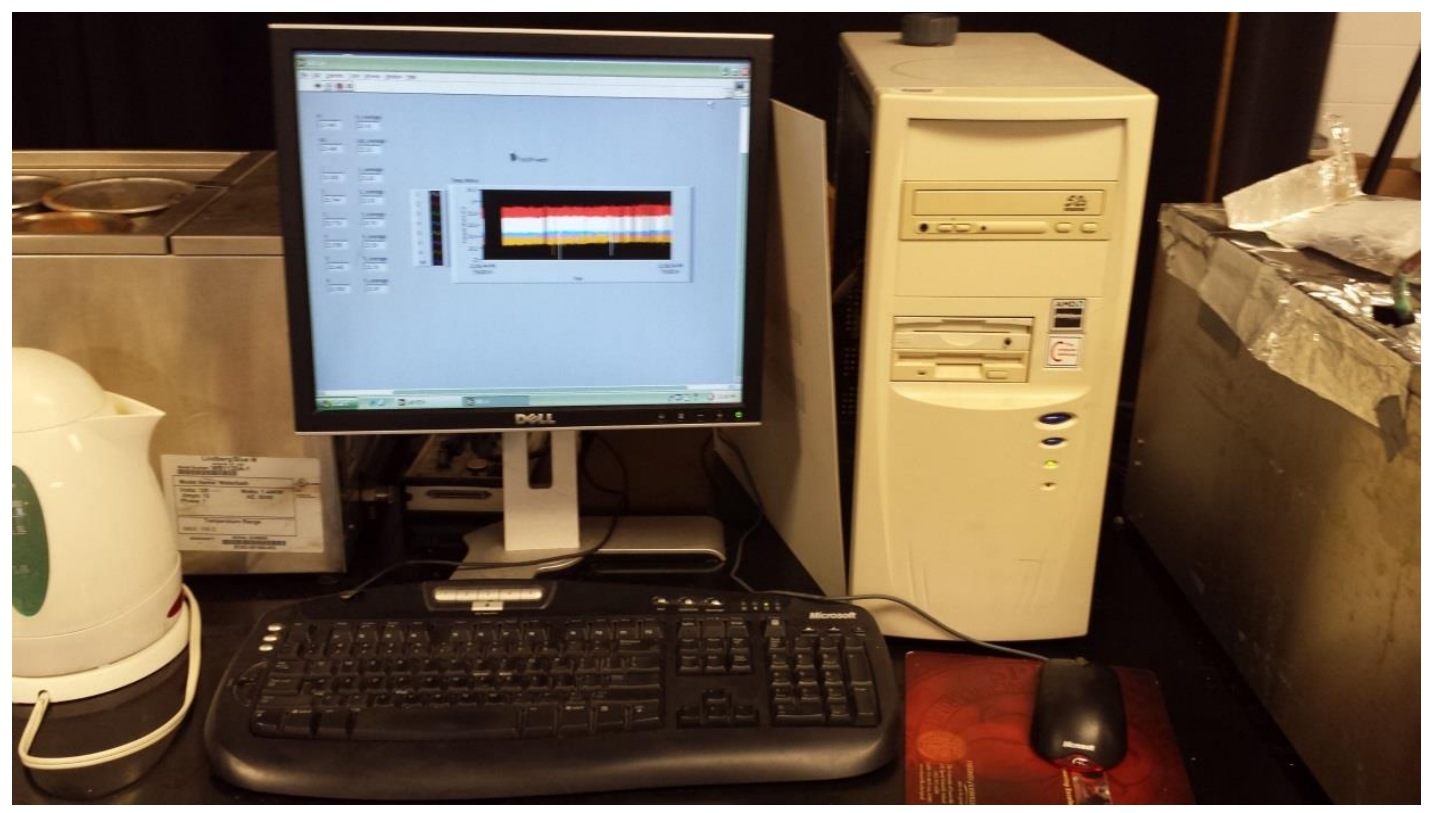

Figure 5 - Computer with Labview used to record readings from temperature probes 
The fluid is loaded into the fluid reservoir which gravity feeds into a variable speed gear pump. The outlet of the gear pump has a positive displacement flow meter with a digital read out. From the flow meter the fluid is pumped through a water bath to adjust the temperature of the fluid to a specified temperature. After the water bath the fluid enters the insulated data acquisition section. Heat is added to the fluid by heat tracing with a constant heat flux. Thermocouples are placed before and after the heat flux portion of piping and at six other places evenly spaced inside the insulated section. These thermocouples are connected to a computer running Labview software to analyze the data. The fluid leaving the heat transfer section is fed back to the heat transfer reservoir.

The fluid reservoir is a piece of copper piping with threaded connection on the top to allow filling. The piping itself has a 2" nominal diameter and is 1 foot tall. This allows the reservoir to hold 1.5 liters of working fluid and also allows enough liquid holdup to maintain required NPSH for the pump.

A Dayton Electric Centrifugal Gear Pump (Model Number: 6NY97) powered by a Dayton Electric Adjustable Speed Motor (Model Number: 1F798) pumps the working fluid. The pump operates at $1 \mathrm{HP}$ of torque when running at the maximum RPM of 1725 . The suction of the pump is supplied by the fluid reservoir and the fluid is discharged into the flow meter.

An Omega Positive Displacement Flowmeter (Model Number: FPD1004) measures fluid flow. This flow meter is designed for measuring the flow rate of highly viscous fluids, and is capable of measuring fluids with viscosities ranging from $0-1000 \mathrm{cP}$. It can 
measure flow rate ranging from 0.26 to $7.9 \mathrm{GPM}$ with a precision of $+/-0.5 \%$. The flow meter is wired to an Omega 6-Digit Rate Meter/Totalizer (Model Number: DPF701).

The cooling bath used is a Thermo Scientific Lindberg Circulating Water Bath (Model Number: WB1120A-1). It has a 7 gallon capacity and has a maximum thermal output of 4776 BTU. The bath can maintain a water temperature of $5{ }^{\circ} \mathrm{C}$ to $100{ }^{\circ} \mathrm{C}$ with a temperature uniformity of $+/-0.1^{\circ} \mathrm{C}$. In order to ensure that the fluid passing through the water bath reaches the equilibrium temperature, several meters of the piping was coiled and placed in the bath, allowing for increased contact time.

The six thermocouples used to measure the surface temperature of the heat transfer section were Omega Ready-Made Insulated Thermocouples (Part\# 5SRTC-TT-T-30-36). It is a Type T thermocouple with 40" of 30 AWG PFA insulated wire with a molded mini connecter with snap-on strain relief. It has a maximum service temperature of $260{ }^{\circ} \mathrm{C}$ with a limit of error of $1{ }^{\circ} \mathrm{C}$.

The inline thermocouples used to measure the temperature of the fluid entering and exiting the heat transfer section is an Omega Rugged Pipe Plug Thermocouple Probe (Part\# TC-T-NPT-U-72-SMP). It is a Type T ungrounded junction thermocouple with $1 / 4$ NPT thread and 72" long extension leads. This thermocouple can be used in systems with pressures up to $2500 \mathrm{psi}$ at ambient temperatures and can measure temperatures up to 650 ${ }^{\circ} \mathrm{C}$. These thermocouples have a limit of error of $1.0^{\circ} \mathrm{C}$.

Omega High Temperature Heater Tape (Model\# FGH101-100) supplied the constant heat flux to the heat transfer section. It is a 1"X10' heat tape that contains 36-40 gauge 
resistance wire insulated by double-braided fiberglass. It can produce 1040 Watts of heat at a voltage input of 120 volts. The lead wires are located at the opposite ends of the heat tape and are connected by an integrally molded separable plug. The heavy duty tape is designed to be used for direct contact with a conductive surface.

A Staco Energy Variable Transformer (Model\# 3PN1010B) is used to regulate the voltage supplied to the heat tape. This is a fully enclosed transformer that converts an input voltage of $120 \mathrm{~V}$ to an output voltage range of $0-140 \mathrm{~V}$. The voltage output is controlled by a dial located on the top of the transformer. At a constant current load it can provide a maximum current of 10.0 Amps. 


\section{PROCEDURE}

\section{Materials}

Carbon coated cobalt nanoparticles were obtained from US-Nano. The particle size is 28 $\mathrm{nm}$ with a cobalt purity of $99.8 \%$. The carbon coating is $0.78 \mathrm{~nm}$ and accounts for 4.28 wt $\%$ of the total particle. Carbon coated copper nanoparticles were also obtained from US-Nano. The particle size is $25 \mathrm{~nm}$ with a copper purity of $99.8 \%$. The carbon coating is $0.66 \mathrm{~nm}$ and accounts for $4.00 \mathrm{wt} \%$ of the total particle. Both particles were synthesized using a pulse-laser evaporation method. The base fluid in which the particles were dispersed was a synthetic polyalphaolefin oil, 0W-30, from AMSoil Corporation.

\section{Nanofluid Preparation}

Nanofluids were prepared for the particle weight percent of $0.50 \%, 1.00 \%$, and $1.50 \%$. To prepare the nanofluid, the appropriate amount of nanoparticles is weighed out and added to $150 \mathrm{~mL}$ of the motor oil contained in a $200 \mathrm{~mL}$ beaker. The mixture is stirred by hand with a stir rod for 5 minutes. After stirring the beaker is placed in a water bath and the sonicator is submerged half way down the beaker. The purpose of the water bath is to help dissipate the large amount of heat generated during the sonication process. The mixture is sonicated at $70 \%$ amplitude for 10 minutes and then let to sit for 10 minutes to dissipate any generated heat. This process is repeated 5 times with manual stirring of the solution before sonication is started again. After the sixth sonication, the mixture is added to the remaining $1050 \mathrm{~mL}$ of motor oil and mixed by hand with a stir rod for 5 minutes. The samples were then allowed to sit overnight to ensure a stable suspension was 
reached. Additional mixing of the fluid will take place during the start-up operation of the heat transfer rig. During this time the fluid will be allowed to circulate for several hours to help ensure a uniform dispersion of the nanoparticles.

\section{Operation of Heat Transfer Rig}

The previously prepared nanofluid is added to the liquid holding reservoir and the system is closed and all seals are checked to ensure they are tightly closed. The pump is turned on to begin circulating the nanofluid through the system at a moderate flow rate, around $70 \mathrm{~mL} / \mathrm{s}$. Next the variable transformer is turned on to begin heating the heat tape. The output voltage is set at $60 \%$ maximum output ( 84 Volts). This setting is used to ensure a sufficient temperature gradient is available in the system, but not large enough to cause the fluid to overheat. Finally the water bath is turned on and set to the first temperature of interest, $50{ }^{\circ} \mathrm{C}$. The fluid is allowed to circulate and heat up until the water bath is reading a constant temperature and all the thermocouple readings have remained constant for at least 10 minutes.

Once the system has reached steady state the flow rate on the pump is changed to one of the desired testing levels. A new Labview program is opened and run to begin data collection for this flow rate. The system is then given enough time to reach steady state, typically 10-15 minutes, and the thermocouple reading have stayed constant for 2-3 minutes. The Labview program is then closed out and the pump is set to another flow rate. In order to help eliminate systematic error and to ensure that clear difference in temperatures is visible, the flow rates are not tested in constant increasing or decreasing 
order. Instead a flow rate with a difference of at least $30 \mathrm{~mL} / \mathrm{s}$ is chosen. An example testing order would be $20,80,40,10,60,100,30 \mathrm{~mL} / \mathrm{s}$. After all desired flow rates are measured the water bath is set to the next temperature, $65^{\circ} \mathrm{C}$, and the process is repeated.

After the final flow rate of the final temperature is measured the water bath and heat tape are turned off to allow the system temperature to drop. It is important to keep the pump running for at least 10 minutes so that any residual heat being supplied by the heat tape can be dissipated to prevent excessive heating of the heat transfer section. Once all the thermocouples begin reading similar values $+/-1{ }^{\circ} \mathrm{C}$, the pump can be turned off and the system is left to cool down for 1-2 hours. After the system is cool the nanofluid is drained from the system and the next nanofluid is prepared.

\section{Calculation of Heat Transfer Coefficient}

The fundamental equation to calculate the convective heat transfer coefficient is as follows.

$$
h=\frac{Q}{T_{w}-T_{f}},
$$

where $\mathrm{h}$ is the convective heat transfer coefficient, $\mathrm{Q}$ is the amount of heat transferred in the system per unit area, $\mathrm{T}_{\mathrm{f}}$ is the temperature of the fluid, and $\mathrm{T}_{\mathrm{w}}$ is the temperature of the wall.

The amount of heat transferred in the system per unit area can be calculated by the fundamental equation that follows. 


$$
Q=\frac{\dot{m} C p \Delta T}{\text { Area }}
$$

where $\mathrm{m}$ is the mass flow rate of the liquid, $\mathrm{Cp}$ is the heat capacity of the liquid, $\Delta \mathrm{T}$ is the temperature difference between the entrance and exit temperature of the liquid, and Area is the inside surface area of the heat transfer section.

Combining Equations 1 and 2 along with some substitutions for calculating area and mass flow rate results in equation 3.

$$
h=\frac{\frac{\left(T_{o}-T_{i}\right) C p \rho \dot{V}}{\pi d L}}{\widetilde{T_{w}}-\widetilde{T_{f}}},
$$

where $\rho$ is the density of the fluid, $V$ is the volumetric flow rate of the nanofluid, $d$ is the inner diameter of the heat transfer piping, and $\mathrm{L}$ is the length of the heat transfer piping. The equation was derived for this system by Starr and Liu. [10]

A spread sheet was built to take all measured variables and calculate the heat transfer coefficient using this equation. All temperatures were taken as an average of the last 10 data points collected while the system was in steady state. The temperature dependent variables, viscosity and specific heat, were interpolated at the average fluid temperature in the heat transfer section. The spread sheet for the copper base fluid at inlet temperature of $40{ }^{\circ} \mathrm{C}$ is shown. 


\begin{tabular}{|c|c|c|c|c|c|c|c|}
\hline Water Bath Temp $\left({ }^{\circ} \mathrm{C}\right)$ & \multicolumn{7}{|c|}{$\mathrm{T}=40 \mathrm{C}$} \\
\hline Flow cc/s & 10 & 20 & 30 & 40 & 60 & 80 & 100 \\
\hline \multicolumn{8}{|l|}{ Temperatures $\left({ }^{\circ} \mathrm{C}\right)$} \\
\hline Inlet & 46.60 & 47.71 & 47.13 & 47.37 & 47.14 & 48.97 & 49.98 \\
\hline 1 & 59.35 & 59.35 & 57.78 & 57.55 & 56.71 & 58.06 & 58.44 \\
\hline 2 & 73.89 & 71.13 & 68.31 & 67.31 & 65.35 & 65.77 & 65.72 \\
\hline 3 & 79.85 & 75.39 & 71.66 & 70.27 & 67.47 & 67.49 & 66.76 \\
\hline 4 & 89.91 & 84.76 & 80.48 & 78.70 & 74.89 & 73.93 & 72.38 \\
\hline 5 & 91.12 & 86.28 & 82.05 & 80.01 & 76.59 & 75.32 & 73.89 \\
\hline 6 & 94.57 & 89.39 & 84.30 & 82.96 & 78.98 & 78.11 & 76.07 \\
\hline Outlet & 64.79 & 59.92 & 55.64 & 54.32 & 51.99 & 52.43 & 52.55 \\
\hline \multicolumn{8}{|l|}{ Fluid Properties } \\
\hline Density $\left(\mathrm{kg} / \mathrm{m}^{3}\right)$ & 853 & 853 & 853 & 853 & 853 & 853 & 853 \\
\hline Viscosity (cP) & 19.57 & 21.07 & 23.21 & 23.71 & 24.96 & 23.85 & 23.32 \\
\hline Specific Heat (J/kg-K) & 1978 & 1968 & 1955 & 1952 & 1946 & 1952 & 1955 \\
\hline \multicolumn{8}{|l|}{ System Values } \\
\hline Average Fluid Temp $\left({ }^{\circ} \mathrm{C}\right)$ & 55.70 & 53.82 & 51.39 & 50.85 & 49.57 & 50.70 & 51.27 \\
\hline $\mathrm{T}_{\text {out }}-\mathrm{T}_{\text {in }}\left({ }^{\circ} \mathrm{C}\right)$ & 18.19 & 12.21 & 8.51 & 6.95 & 4.85 & 3.46 & 2.57 \\
\hline Average $\mathrm{T}_{\text {wall }}-\mathrm{T}_{\text {fluid }}\left({ }^{\circ} \mathrm{C}\right)$ & 25.75 & 23.90 & 22.71 & 21.96 & 20.43 & 19.08 & 17.61 \\
\hline Total Heat In $(\mathrm{W})$ & 310 & 414 & 430 & 460 & 483 & 462 & 430 \\
\hline Total Heat Flux $\left(\mathrm{W} / \mathrm{m}^{2}\right)$ & 18,854 & 25,186 & 26,162 & 28,003 & 29,367 & 28,093 & 26,164 \\
\hline \multicolumn{8}{|l|}{ System Properties } \\
\hline Reynolds \# & 117 & 217 & 295 & 379 & 544 & 760 & 974 \\
\hline $\begin{array}{l}\text { Heat Transfer Coefficient } \\
\qquad\left(\mathrm{W} / \mathrm{m}^{2}-\mathrm{K}\right)\end{array}$ & 732 & 1054 & 1152 & 1275 & 1437 & 1472 & 1486 \\
\hline
\end{tabular}

Table 1 - Spreadsheet used to calculate heat transfer coefficient of PAO base fluid used for carbon coated copper nanofluid dispersions at $40{ }^{\circ} \mathrm{C}$ 


\section{RESULTS AND DISCUSSION}

\section{Creating a Stable Suspension}

It is generally accepted that the more homogeneously dispersed the nanoparticles are in the base fluid, the higher the resulting heat transfer enhancement. With that in mind it is very important to verify that the carbon coated metal nanoparticles would be able to be dispersed and create a lasting stable suspension. Prior to the synthesis of the large scale (1.2 liter) batches of nanofluid small batches of nanofluids $(50 \mathrm{~mL})$ were created to ensure the stability. The motor oil was added to a small $65 \mathrm{~mL}$ sample vial and nanoparticles were added to create a fluid with a concentration of $1.75 \mathrm{wt} \%$. This concentration was chosen because it was slightly higher than the highest concentration of nanoparticles that would be used in the future experiments and thus if a stable suspension could be reached at this concentration, a stable suspension should be achievable at all other needed concentrations.

The fluid was then sonicated using the $1 / 4$ inch microtip attachment to the ultrasonic dismembrator. The samples were sonicated for 45 minutes at a sonication amplitude of $40 \%$. After the sonication the samples were allowed to sit and were visually inspected for sedimentation periodically. The carbon coated copper nanoparticle dispersion showed excellent stability with no noticeable sedimentation after $30+$ days. The carbon coated cobalt nanoparticles showed less stability, but were still able to stay suspended for at least four days without any noticeable sedimentation. These results proved that stable 
suspensions of carbon coated metal nanoparticles in PAO motor oil was possible without the use of any dispersing agents.

The superior stability of these metal nanoparticles is attributed to the $\sim 1 \mathrm{~nm}$ carbon layer present on the nanoparticles. The most probable explanation for the difference in the stability of the nanoparticles is due to the size differences between the two nanoparticles. The cobalt nanoparticle is $28 \mathrm{~nm}$ whereas the copper nanoparticle is $25 \mathrm{~nm}$. By calculating the volume of the particle and multiplying by the density, an average weight difference of $25 \%$ is present between the two nanoparticles. The larger and heavier cobalt nanoparticles would then fall out of suspension faster than the smaller and lighter copper nanoparticles.

\section{Viscosity Results}

Viscosity was measured for both base fluids and for all nanofluid loading concentrations. In order to identify that all nanofluids exhibited Newtonian behavior, three shear rates were used when measuring fluid viscosity. These three shear rates were then averaged to determine viscosity at the tested temperature. The temperatures tested were $45,60,75,95$ ${ }^{\circ} \mathrm{C}$ within $+/-2{ }^{\circ} \mathrm{C}$. The results from calculating viscosity for the cobalt based fluid is shown in Table 2.

\begin{tabular}{|c|c|c|c|c|c|c|c|c|c|c|c|}
\hline \multicolumn{3}{|c|}{$\mathrm{T}=43.5$} & \multicolumn{3}{|c|}{$\mathrm{T}=61.7$} & \multicolumn{3}{|c|}{$\mathrm{T}=78.2$} & \multicolumn{3}{|c|}{$\mathrm{T}=92.7$} \\
\hline Shear Rate & Shear Stress & Viscosity & Shear Rate & Shear Stress & Viscosity & Shear Rate & Shear Stress & Viscosity & Shear Rate & Shear Stress & Viscosity \\
\hline 300 & 91 & 30.3 & 300 & 48.0 & 16.0 & 300 & 27.0 & 9.0 & 300 & 17.0 & 5.7 \\
\hline 600 & 180 & 30.0 & 600 & 94.0 & 15.7 & 600 & 53.0 & 8.8 & 600 & 34.0 & 5.7 \\
\hline 750 & 223 & 29.7 & 900 & 138.0 & 15.3 & 900 & 81.0 & 9.0 & 900 & 51.0 & 5.7 \\
\hline & Average & 30.0 & & Average & 15.7 & & Average & 8.9 & & Average & 5.7 \\
\hline
\end{tabular}

Table 2 - Viscosity results for cobalt base fluid at various temperatures and shear rates 
The four temperatures and their viscosities were then plotted and a 3rd order polynomial regression was fit to the data. An equation of this form was chosen due to its ability to precisely fit the data collected by the viscometer. This regression equation allows the accurate interpolation of all fluid viscosities at their respective temperatures. The graph and regression equation for the cobalt $0.5 \mathrm{wt} \%$ nanofluid is shown. Trend lines and graphs of all the remaining nanofluids are contained in the appendix.

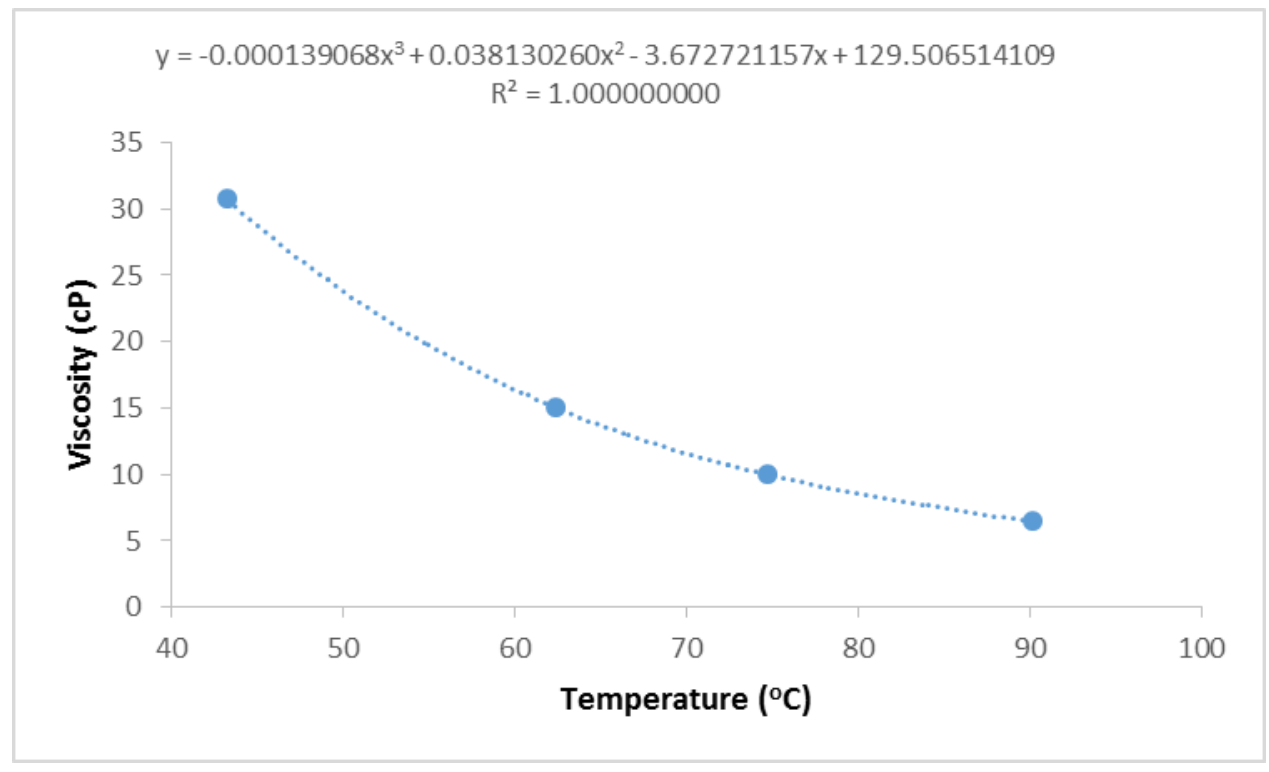

Figure 6 - Viscosity of carbon coated cobalt nanofluid dispersed in PAO base fluid at a loading concentration of $0.5 \mathrm{wt} \%$ as a function of temperature

To compare how the addition of nanoparticles affected the viscosity of the base fluid, viscosities were calculated at several reference temperatures using the regression equations. The regression equations had to be utilized due to the fact that the viscosities directly measured by the viscometer were not at exactly the same temperatures for all of 
the fluids. Graphs showing these calculated viscosities as a function of temperature and nanoparticle loading are shown in Figures 7 and 8.

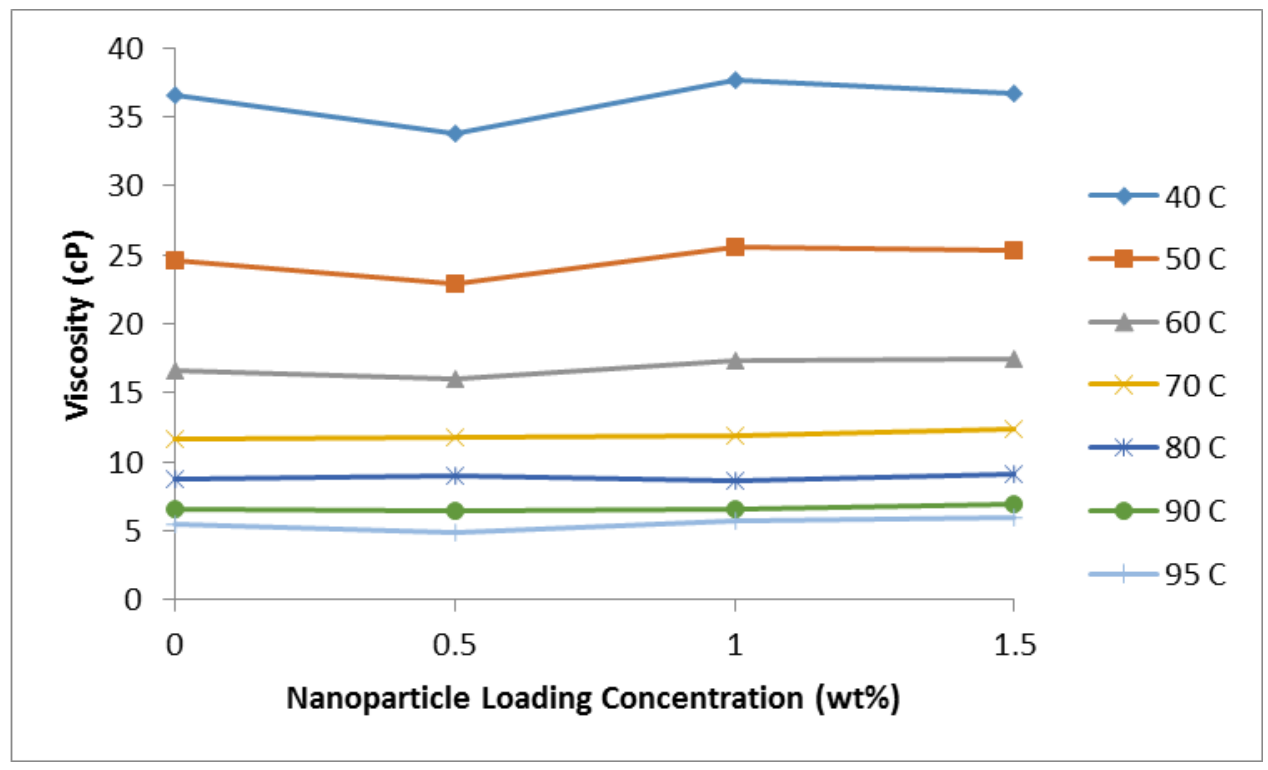

Figure 7 - Viscosities of carbon coated copper nanofluids dispersed in PAO at different loading concentrations and temperatures

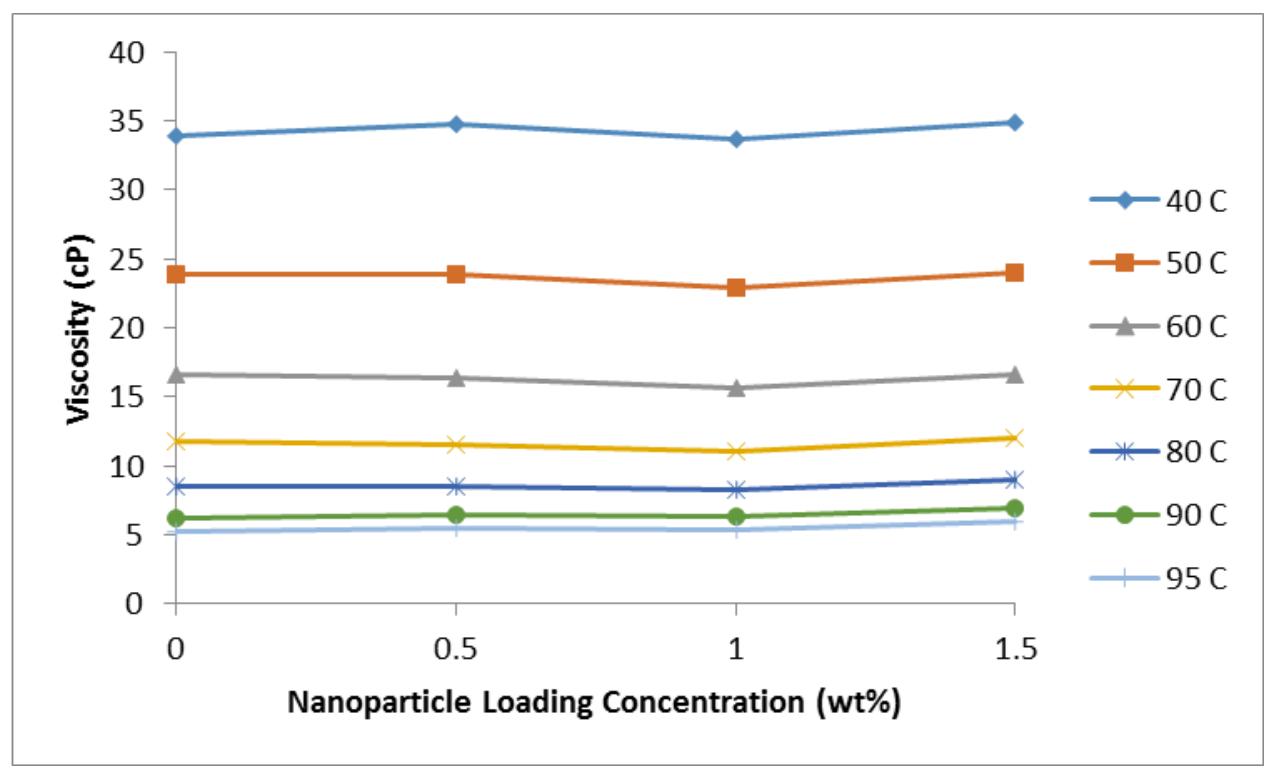

Figure 8 - Viscosities of carbon coated cobalt nanofluids dispersed in PAO at different loading concentrations and temperatures 
When analyzing the viscosity data for the copper based nanofluids, there is a slight decrease in viscosity at a concentration of $0.5 \mathrm{wt} \%$. The viscosity then gradually increases as the concentration is increased to a point where at $1.5 \mathrm{wt} \%$ the average viscosity is 5\% higher than that of the base fluid. A similar trend is noticed in the case of the cobalt based nanofluids with small differences. For this fluid the viscosity at a concentration of $0.5 \mathrm{wt} \%$ is greater than that of the base fluid; however, the viscosity drops below that of the base fluid at $1.0 \mathrm{wt} \%$. At the final concentration the viscosity reaches an average value of 5\% higher than the base fluid.

The general trend recognized by nanofluids is that when the concentration of nanoparticles increases, the viscosity also increases, as observed by Prasher et al. [12] While in general this trend is observed in the data collected for these fluids, the concentrations where the viscosity is lower than that of the base fluid disagree with that trend. A possible explanation for this contradiction could be because of the very small loading concentrations being used in this research. Most reported data for viscosity trends in nanofluids deal with fluids at or above $1.0 \%$ by volume. In this experiment the largest volume concentration is $0.15 \%$ meaning that a decrease in viscosity could be possible at very low particle concentrations. This trend of a decrease in viscosity has been reported by Rucker in systems where nanoparticle concentrations are $<1$ vol\%, however the drop in viscosity is much larger in their fluids. [11] 


\section{Heat Capacity Results}

Heat capacities for all fluids were calculated using DSC over a range of $40-110^{\circ} \mathrm{C}$ in increments of $2{ }^{\circ} \mathrm{C}$. This range covers all temperatures that were tested in the heat transfer rig. All of the fluids heat capacities exhibit a linear dependence on temperature, as expected, and fit a linear regression with an $\mathrm{R}^{2}>0.98$. In the case of the carbon coated copper nanofluids, all of the heat capacities were calculated to be higher than that of the base fluid as shown in Figure 9. There is a large initial increase in heat capacity that stays relatively constant for both $0.5 \mathrm{wt} \%$ and $1.0 \mathrm{wt} \%$, and drops closer to the value of the base fluid at a loading of $1.5 \mathrm{wt} \%$.

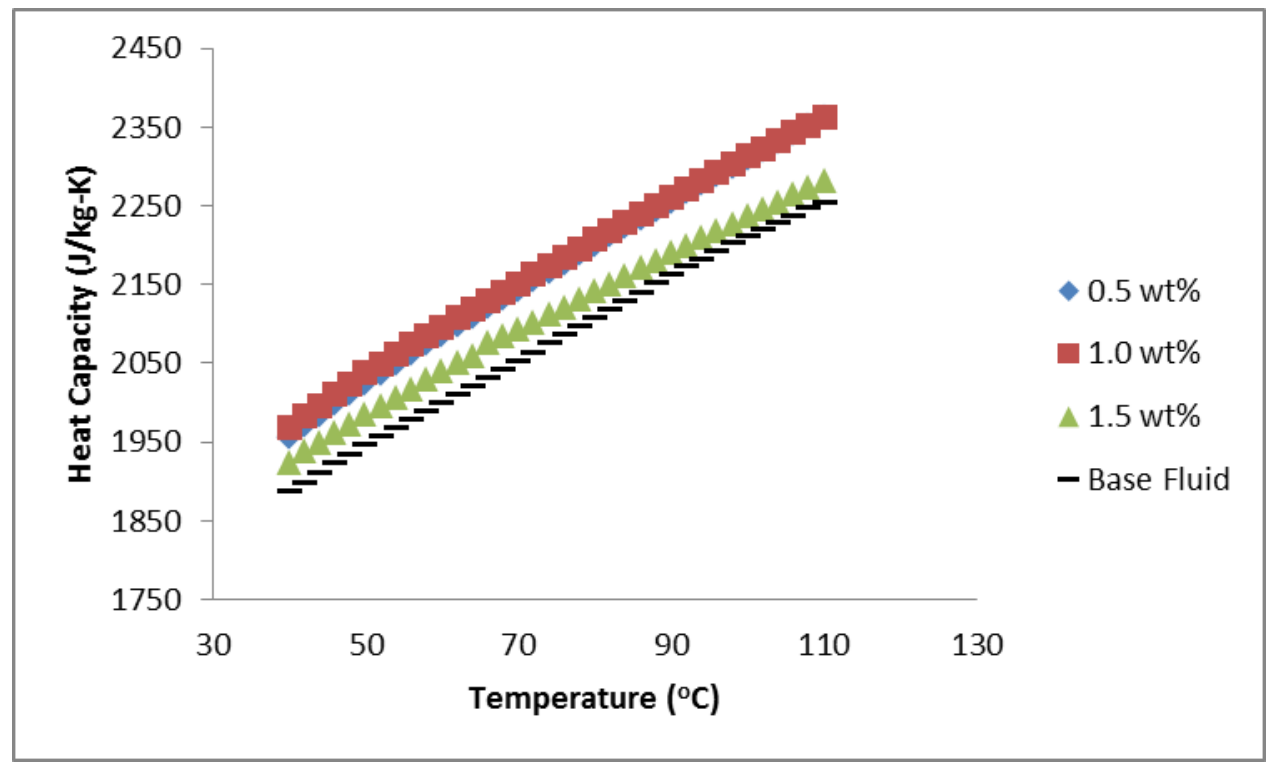

Figure 9 - Heat capacities of carbon coated copper nanofluids dispersed in PAO at different loading concentrations and temperatures

Generally it is expected that the heat capacity for nanofluids should be lower than their base fluids since the heat capacity of the nanoparticles are lower than that of the base 
fluid. A trend which is more closely shown in the data collected for the carbon coated cobalt nanoparticles shown in Figure 10.

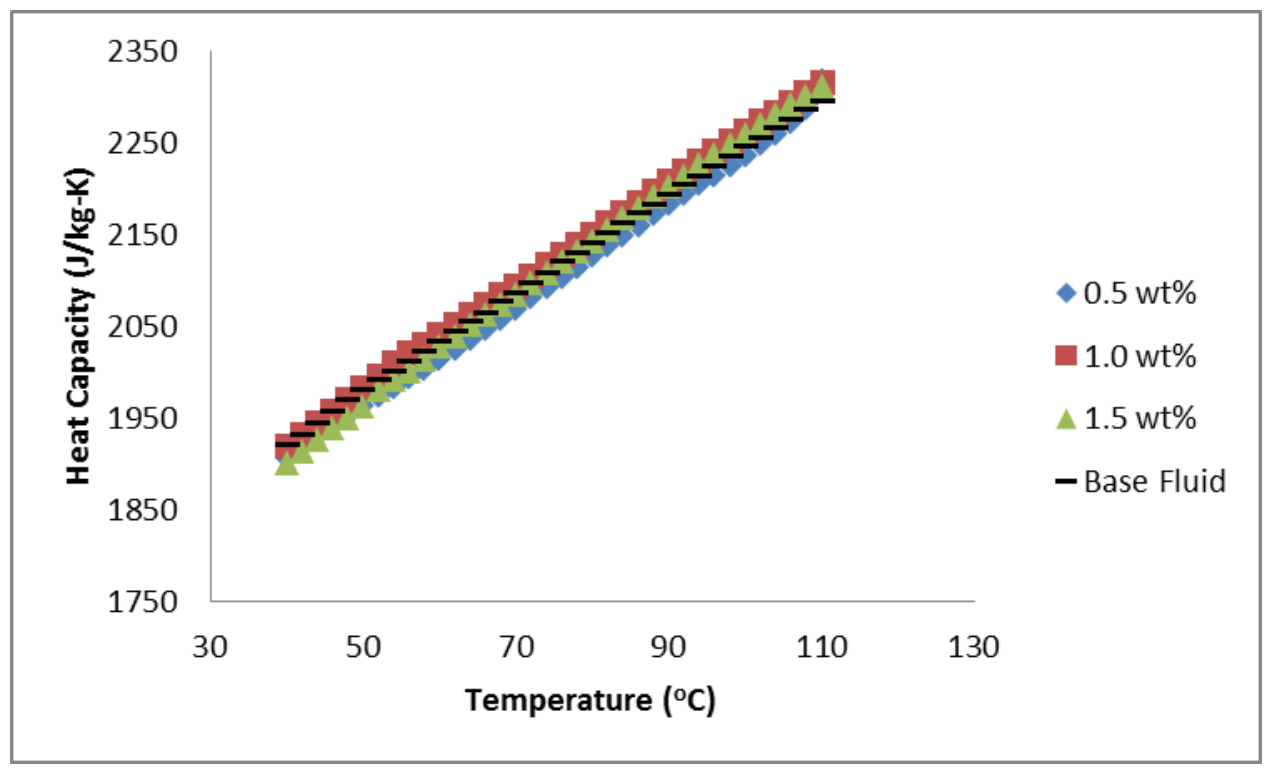

Figure 10 - Heat capacities of carbon coated cobalt nanofluids dispersed in PAO at different loading concentrations and temperatures

This data shows an initial drop in heat capacity at the lowest loading concentration of 0.5 $\mathrm{wt} \%$ that slowly increases as the concentration increases.

The general trend observed in nanofluids is that as the concentration of nanoparticles increases the heat capacity of the fluid decreases. Zhu and Ni have conducted extensive measurements of the heat capacity of nanofluids and the equation that they report to fit their data is Equation 4.

$$
c_{p, n f}=\frac{\emptyset\left(\rho c_{p}\right)_{n}+(1-\varnothing)\left(\rho c_{p}\right)_{f}}{\emptyset \rho_{n}+(1-\varnothing) \rho_{f}}
$$


Based on this equation the heat capacity of the nanofluids should always decrease as the concentration of nanoparticles increases as long as the heat capacity of the nanoparticle is lower than that of the base fluid. Nowhere in their results did they report a heat capacity higher than that of the base fluid, as observed in these fluids. Using Equation 4 the following graphs were generated for the nanoparticle systems present in this report

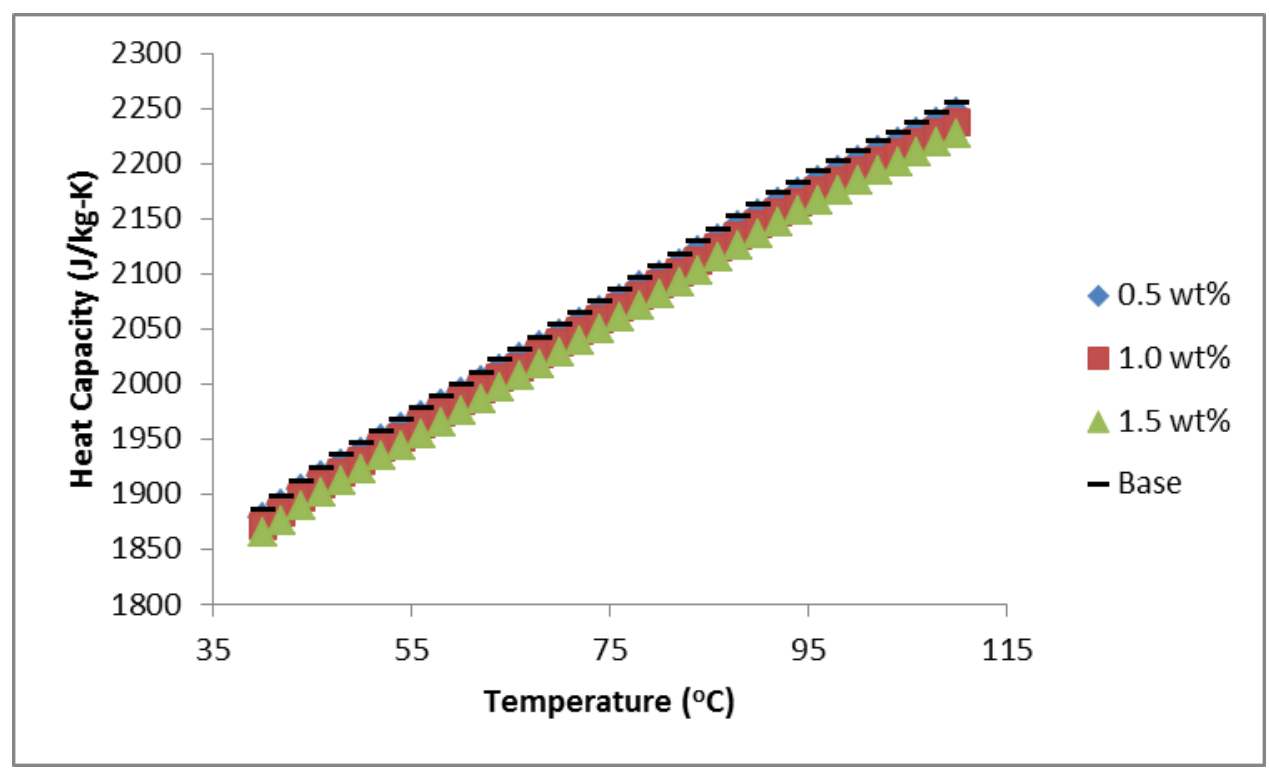

Figure 11 - Theoretical heat capacities of carbon coated copper nanofluids dispersed in PAO at different loading concentrations and temperatures 


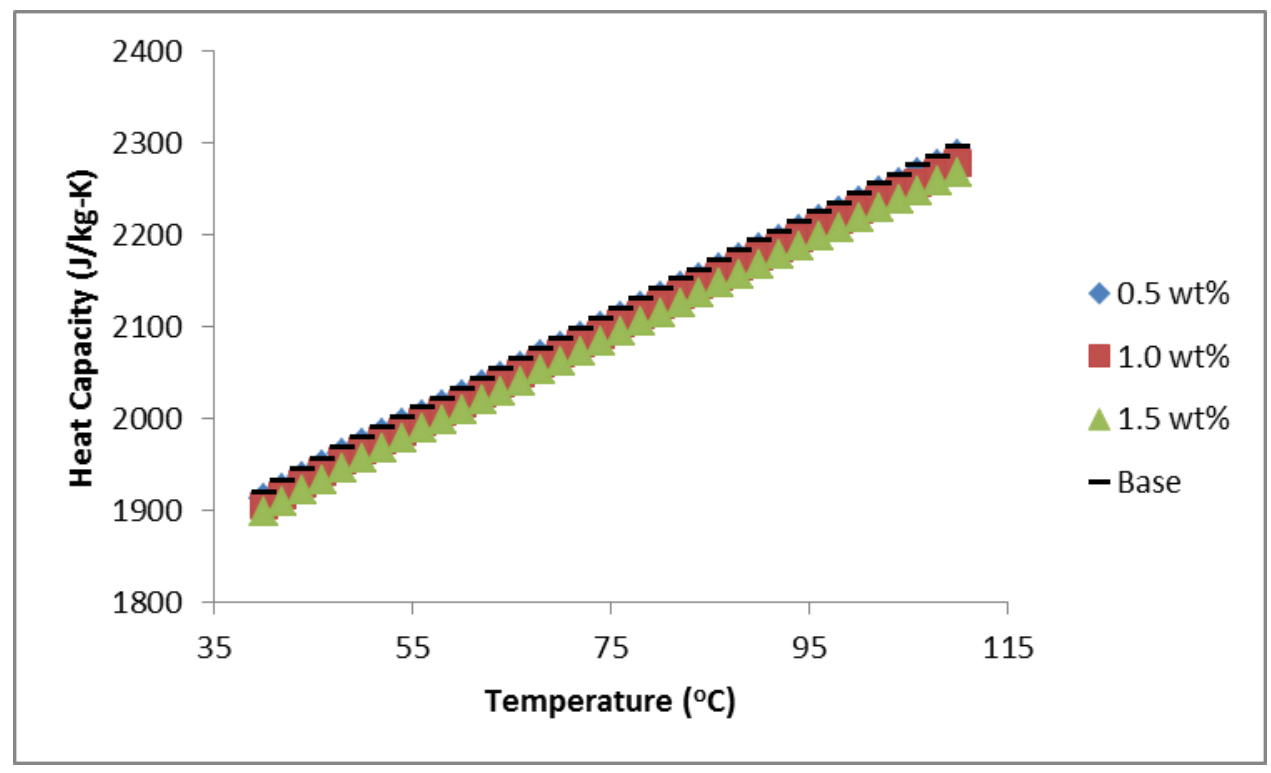

Figure 12 - Theoretical heat capacities of carbon coated cobalt nanofluids dispersed in $\mathrm{PAO}$ at different loading concentrations and temperatures

This discrepancy could be attributed to the fact that the concentration of nanoparticles in this study is much lower than those used in their study. Rucker has reported that at lower volume concentrations the trends proposed by Zhou and Ni may not hold. [11]

\section{Heat Transfer Coefficient}

\section{Carbon Coated Copper Nanoparticles}

Nanofluids containing carbon coated copper nanoparticles were prepared at three different loading concentrations, $0.5 \mathrm{wt} \%, 1.0 \mathrm{wt} \%$, and $1.5 \mathrm{wt} \%$. Heat transfer coefficients were then calculated for various flow rates between 10 and $100 \mathrm{~mL} / \mathrm{s}$ at inlet temperatures of 50,65 , and $90^{\circ} \mathrm{C}$. These values were chosen in order to remain consistent with previous research done in the group. The results for all of the trials are shown in Figures 13, 14, and 15. 


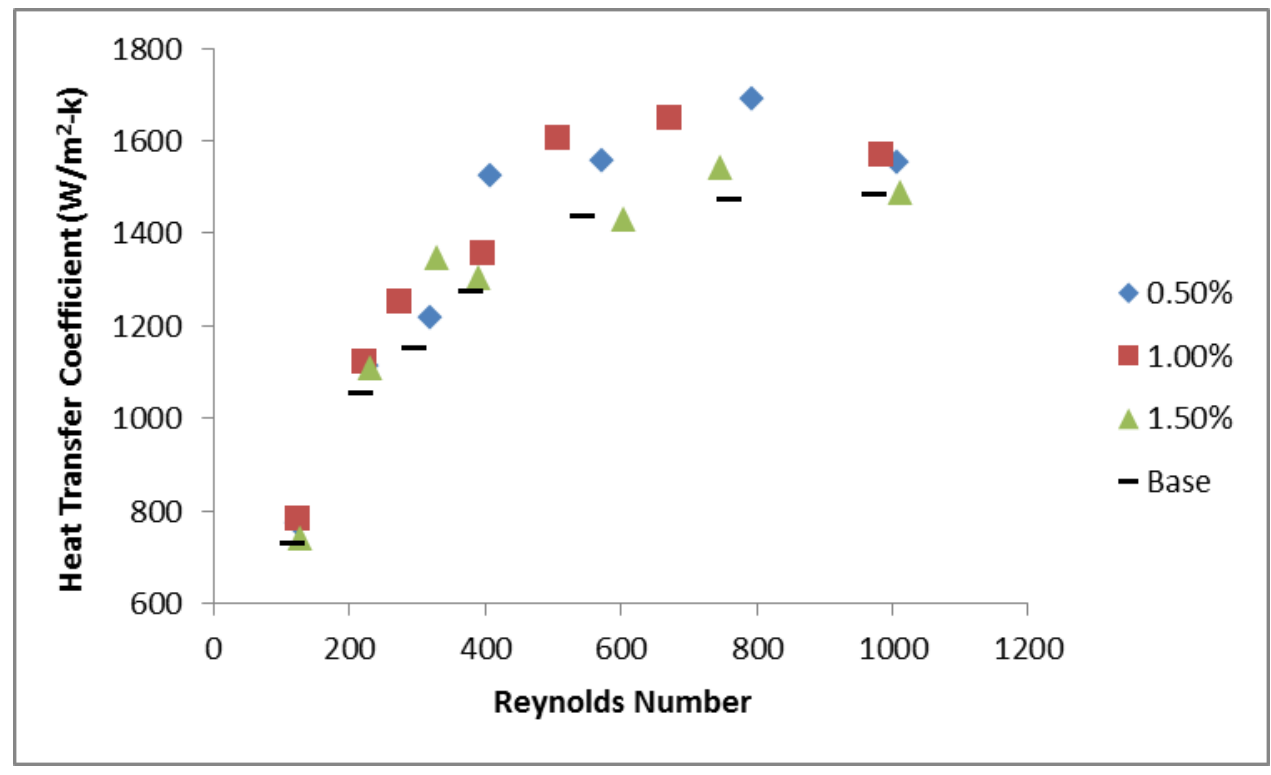

Figure 13 - Heat transfer coefficients of carbon coated copper nanofluids dispersed in $\mathrm{PAO}$ at different loading concentrations as a function of Reynolds Number at $50{ }^{\circ} \mathrm{C}$

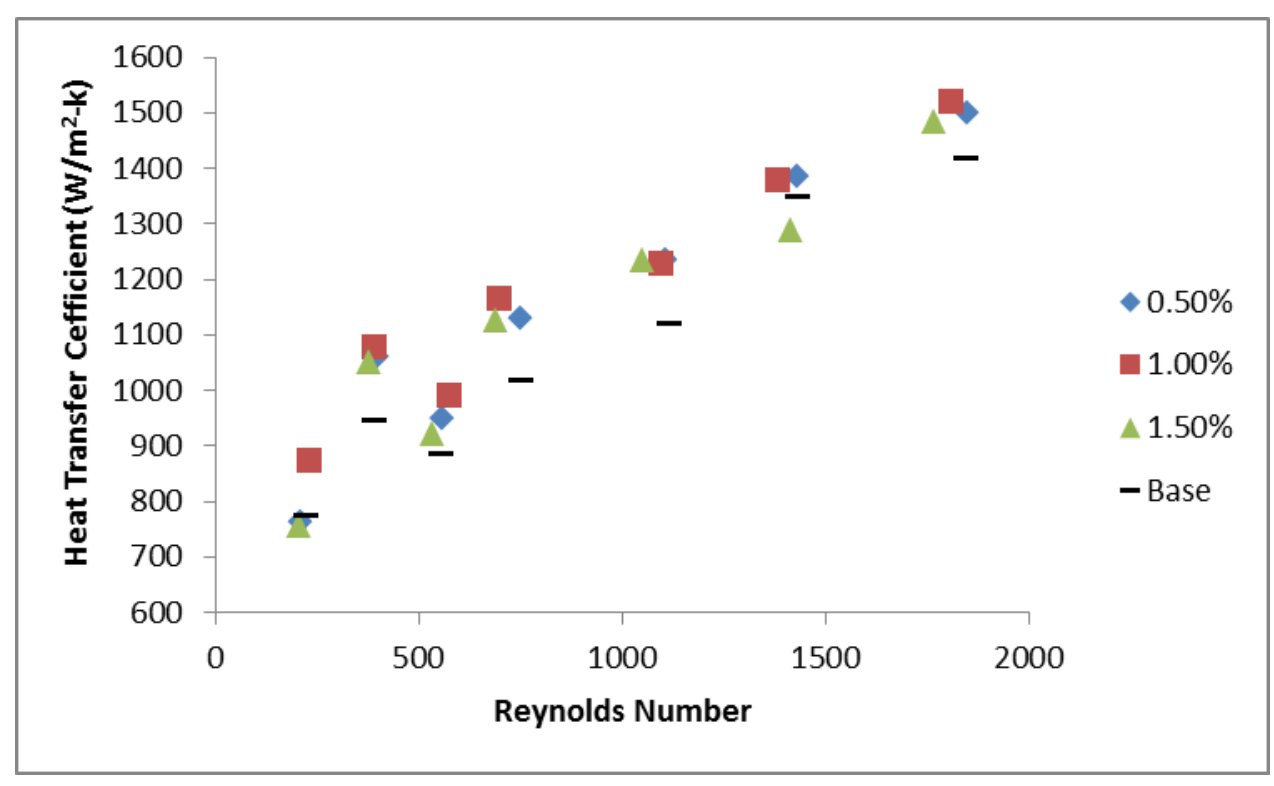

Figure 14 - Heat transfer coefficients of carbon coated copper nanofluids dispersed in PAO at different loading concentrations as a function of Reynolds Number at $65{ }^{\circ} \mathrm{C}$ 


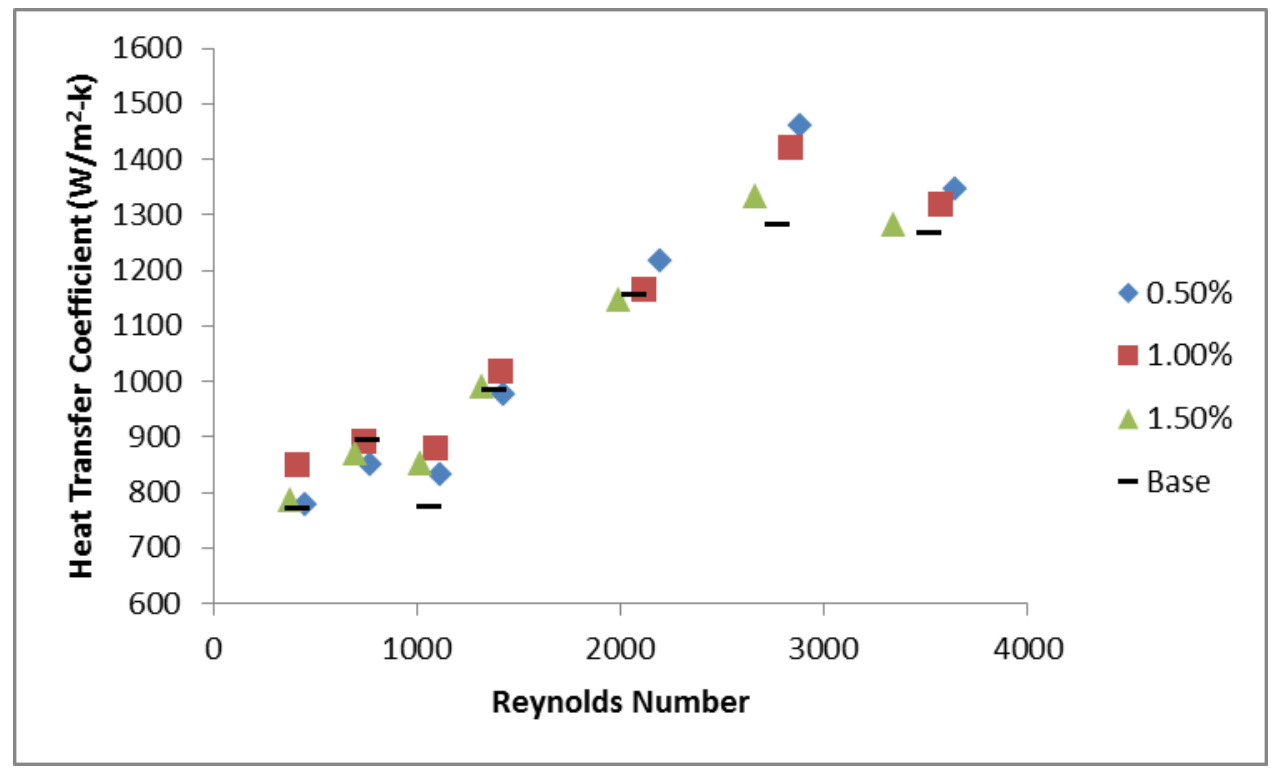

Figure 15 - Heat transfer coefficients of carbon coated copper nanofluids dispersed in PAO at different loading concentrations as a function of Reynolds Number at $90{ }^{\circ} \mathrm{C}$

In order to determine the heat transfer enhancement of the nanofluids, the heat transfer coefficients of the nanofluid is divided by the heat transfer coefficient of the base fluid at the same flow rate. Heat transfer enhancements for these fluids are shown in Figures 16, 17 , and 18. 


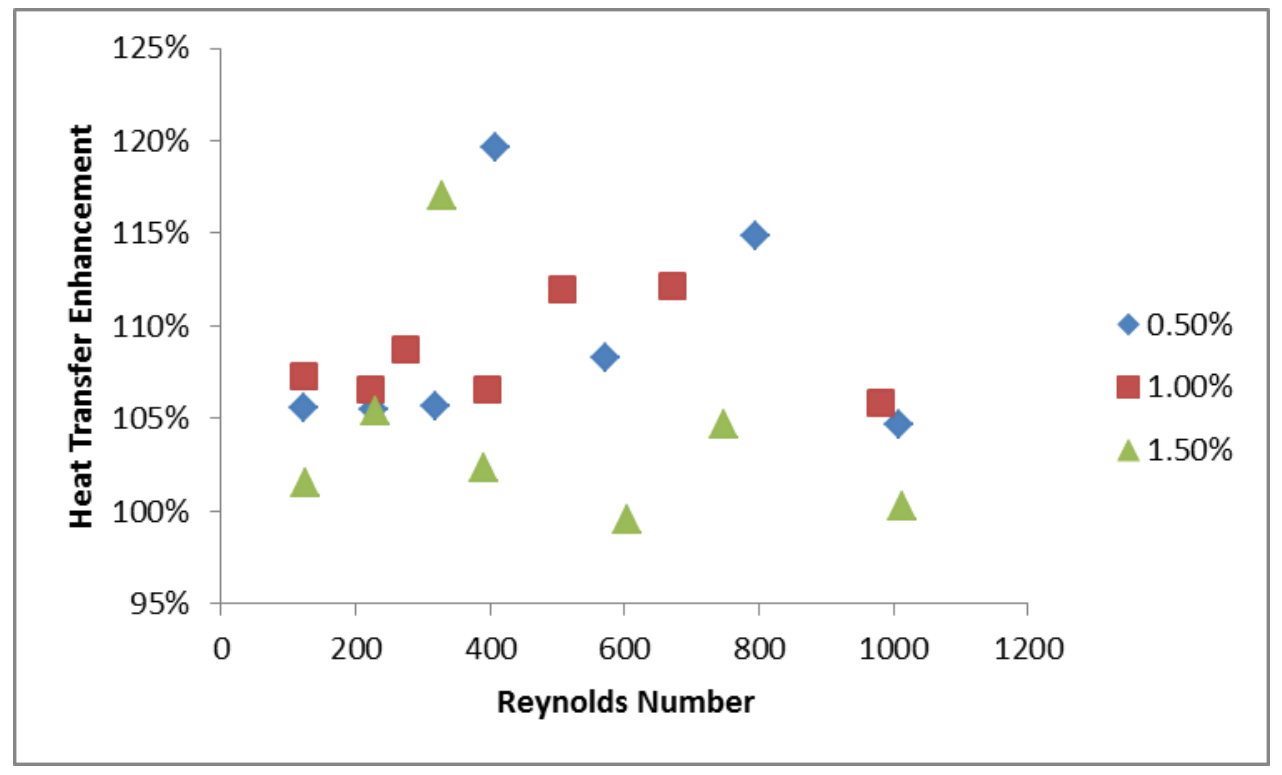

Figure 16 - Heat transfer enhancement of carbon coated copper nanofluids dispersed in $\mathrm{PAO}$ at different loading concentrations as a function of Reynolds Number at $50{ }^{\circ} \mathrm{C}$

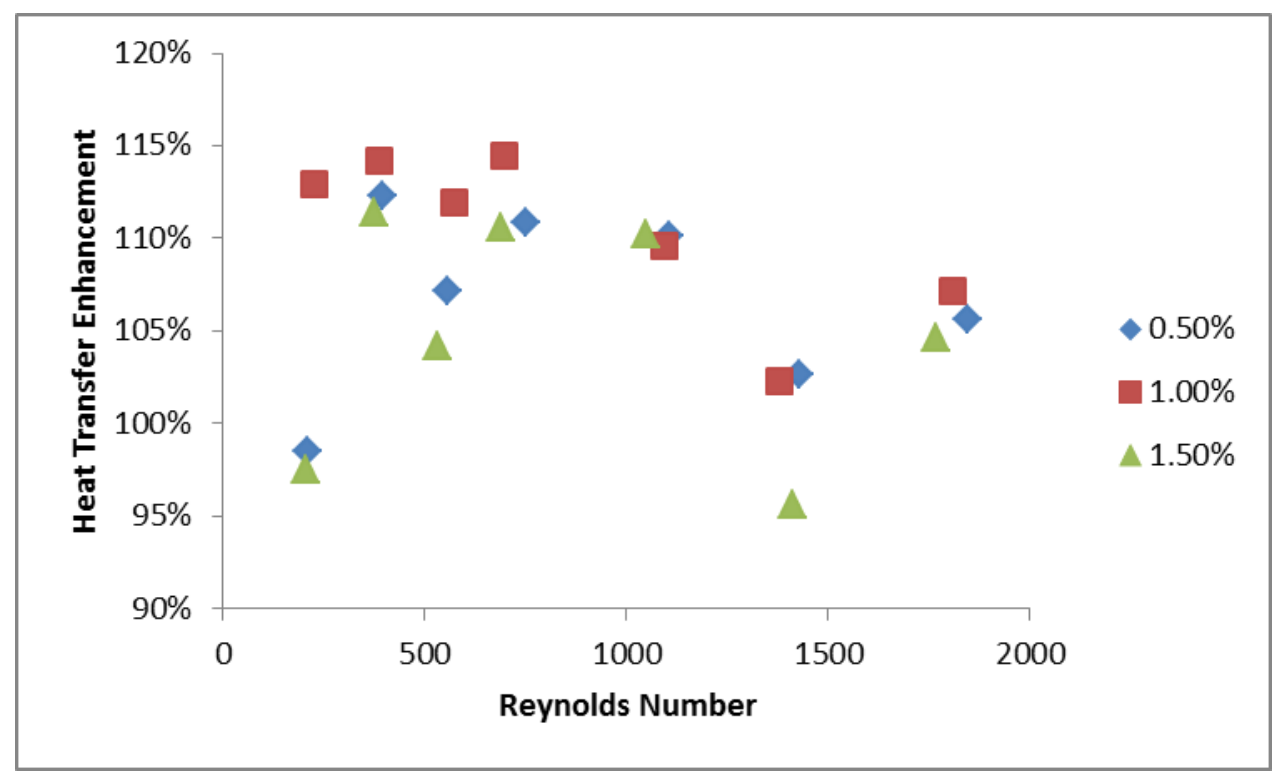

Figure 17 - Heat transfer enhancement of carbon coated copper nanofluids dispersed in PAO at different loading concentrations as a function of Reynolds Number at $65{ }^{\circ} \mathrm{C}$ 


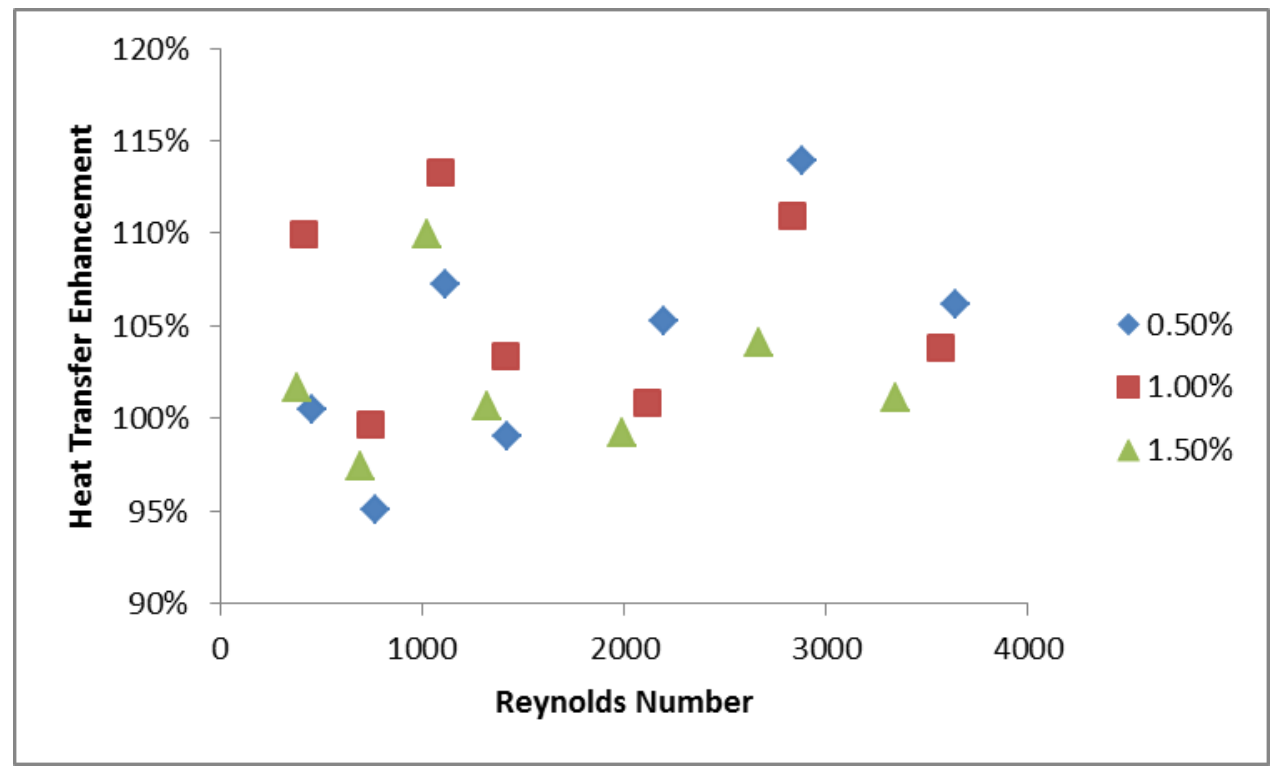

Figure 18 - Heat transfer enhancement of carbon coated copper nanofluids dispersed in PAO at different loading concentrations as a function of Reynolds Number at $90{ }^{\circ} \mathrm{C}$

\section{Carbon Coated Cobalt Nanoparticles}

Nanofluids containing carbon coated cobalt nanoparticles were prepared at the same loading concentrations as the copper nanoparticles $(0.5,1.0,1.5 \mathrm{wt} \%)$. Their heat transfer coefficients were also calculated at the same flow rates $(10-100 \mathrm{~mL} / \mathrm{s})$ and inlet temperatures $\left(50,65,90^{\circ} \mathrm{C}\right)$ as the copper fluid. The calculated heat transfer coefficients are shown in Figures 19, 20, and 21. 


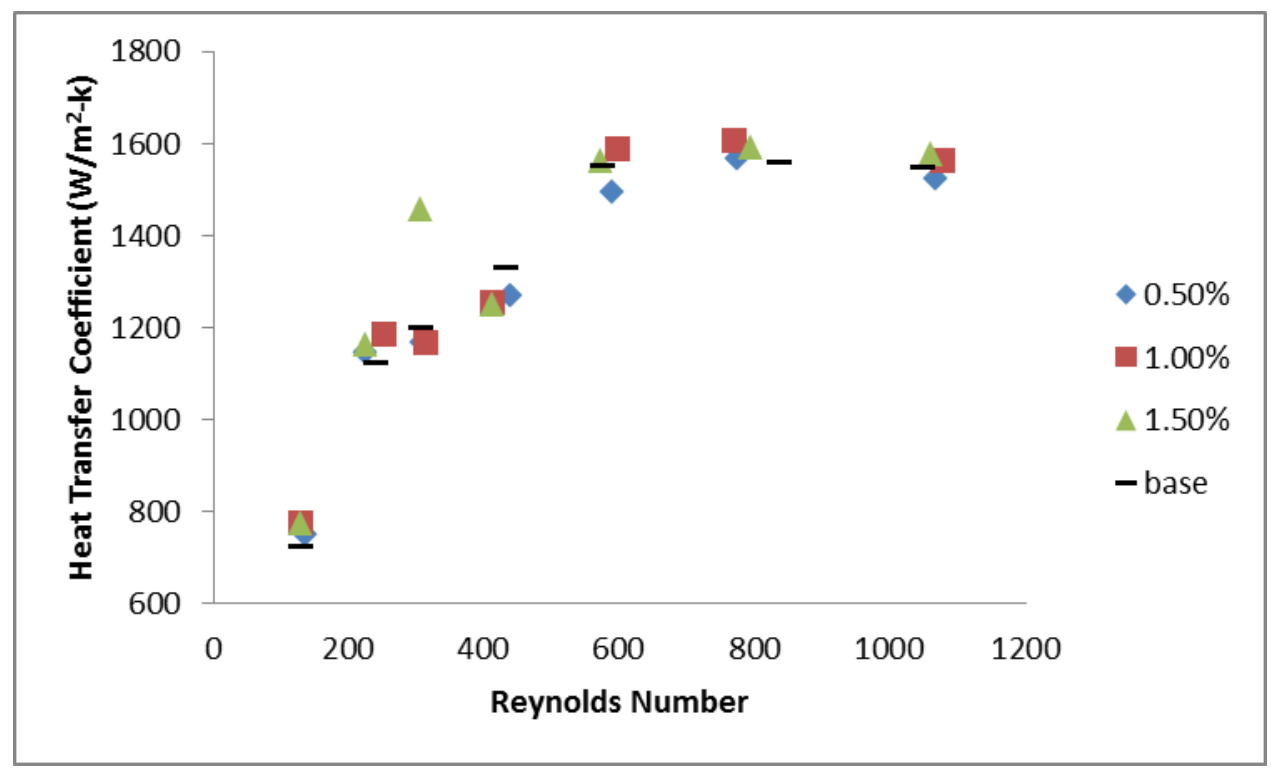

Figure 19 - Heat transfer coefficients of carbon coated cobalt nanofluids dispersed in PAO at different loading concentrations as a function of Reynolds Number at $50{ }^{\circ} \mathrm{C}$

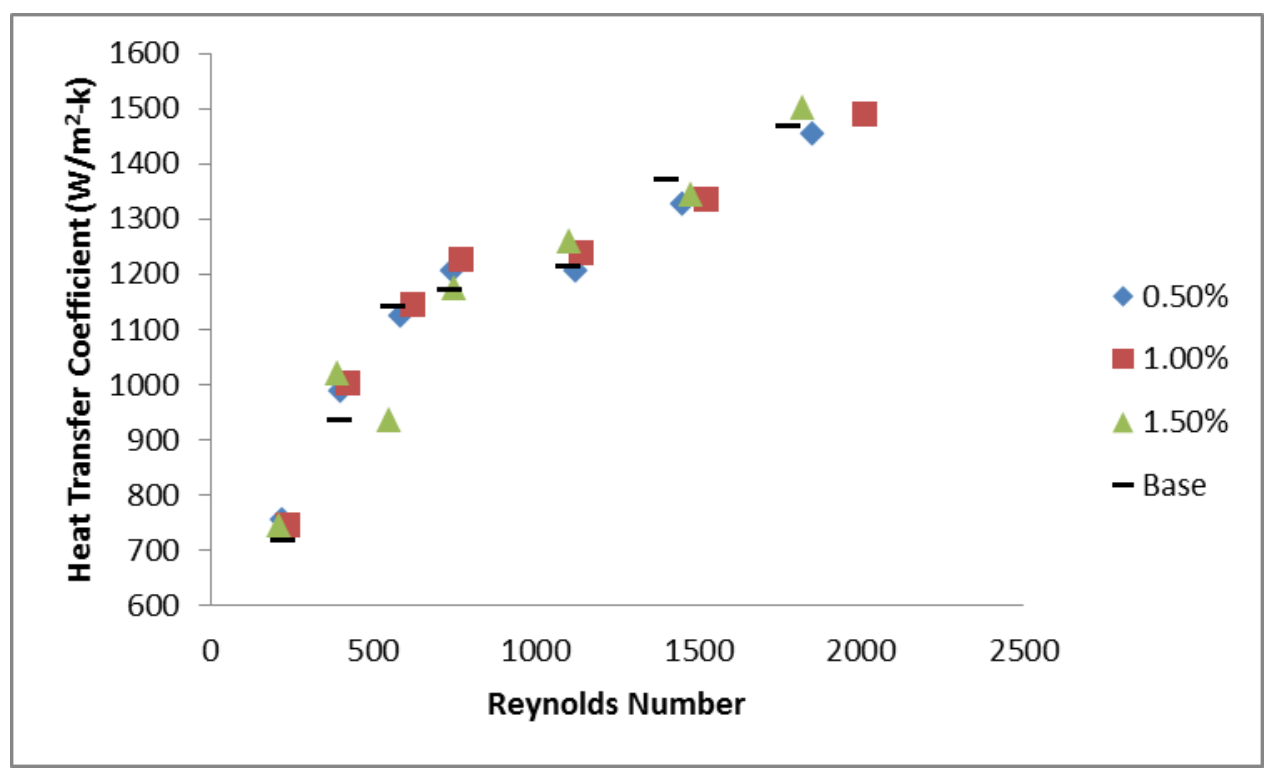

Figure 20 - Heat transfer coefficients of carbon coated cobalt nanofluids dispersed in PAO at different loading concentrations as a function of Reynolds Number at $65{ }^{\circ} \mathrm{C}$ 


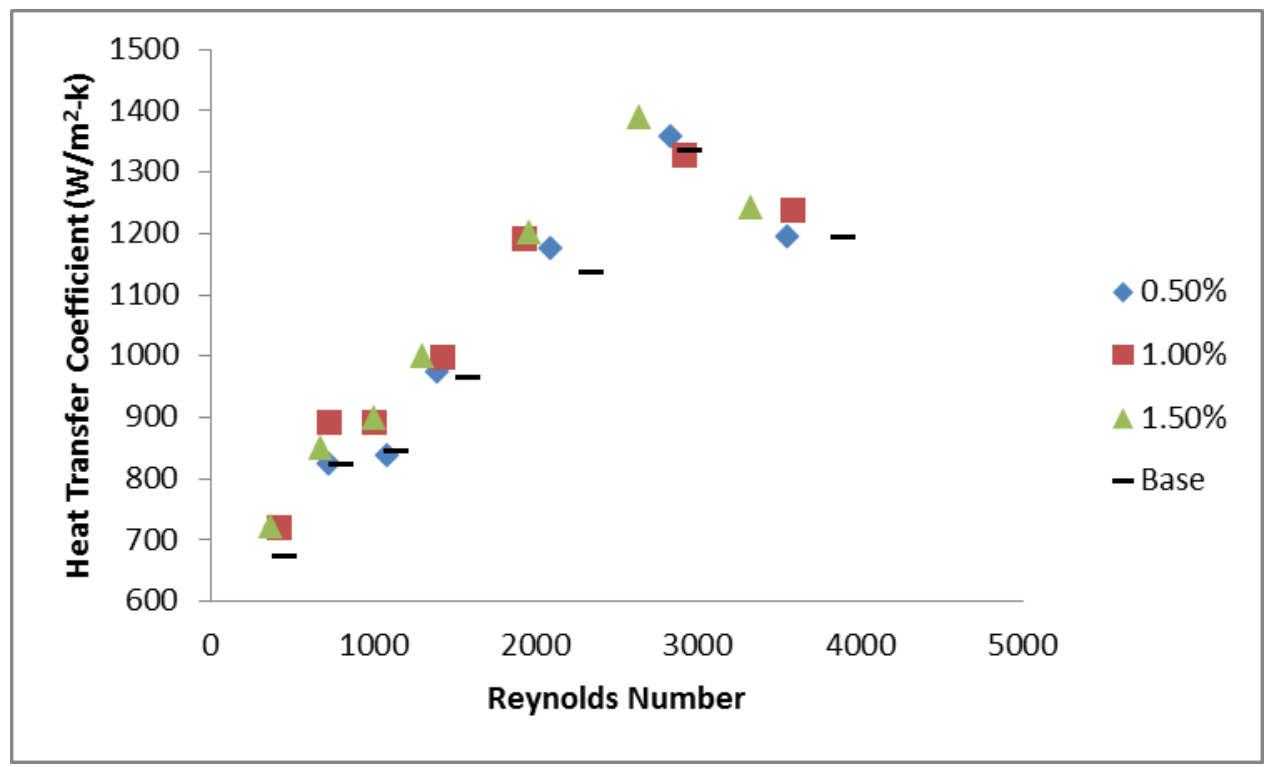

Figure 21 - Heat transfer coefficients of carbon coated cobalt nanofluids dispersed in PAO at different loading concentrations as a function of Reynolds Number at $90{ }^{\circ} \mathrm{C}$

The heat transfer enhancements of these fluids were calculated in the same manner as the heat transfer enhancements in the copper nanofluids. This is done by dividing the heat transfer coefficient of the nanofluid by the correlating heat transfer coefficient of the base fluid. Again these values are shown plotted against their Reynolds Numbers in Figures 22,23 , and 24. 


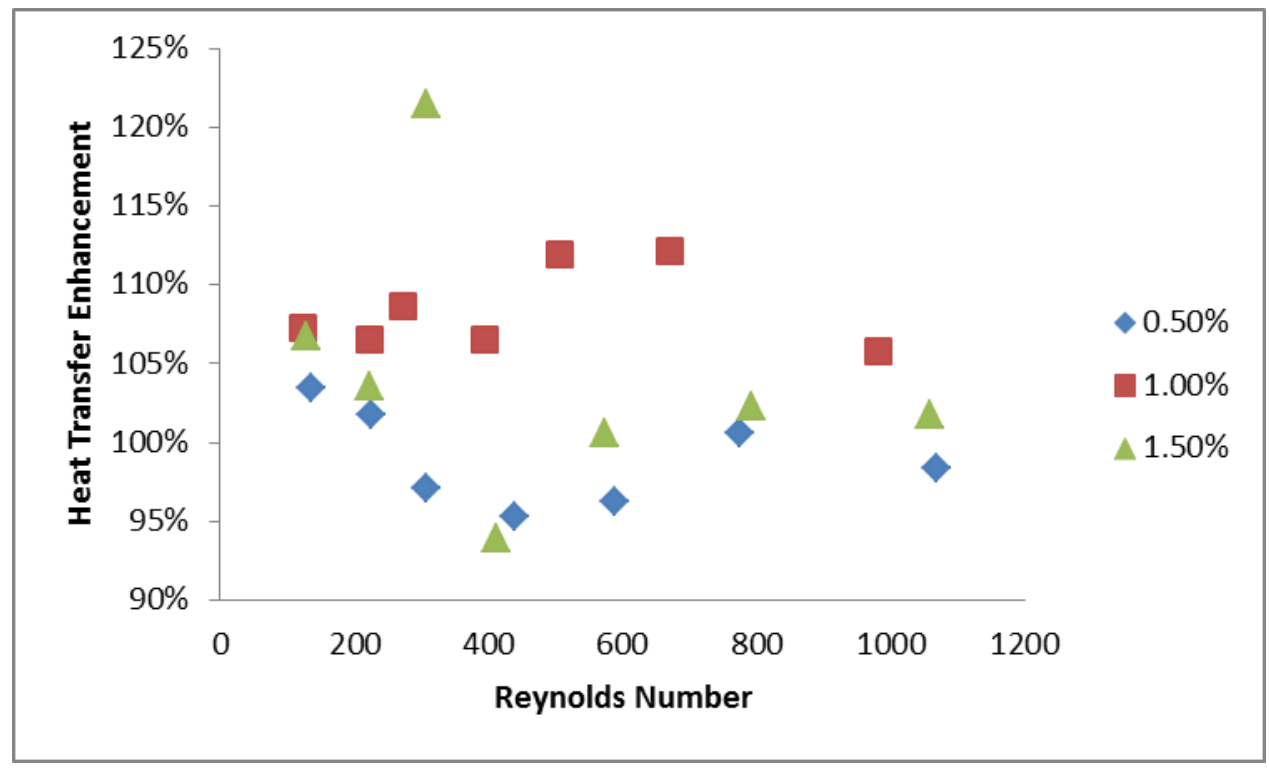

Figure 22 - Heat transfer enhancement of carbon coated cobalt nanofluids dispersed in PAO at different loading concentrations as a function of Reynolds Number at $50{ }^{\circ} \mathrm{C}$

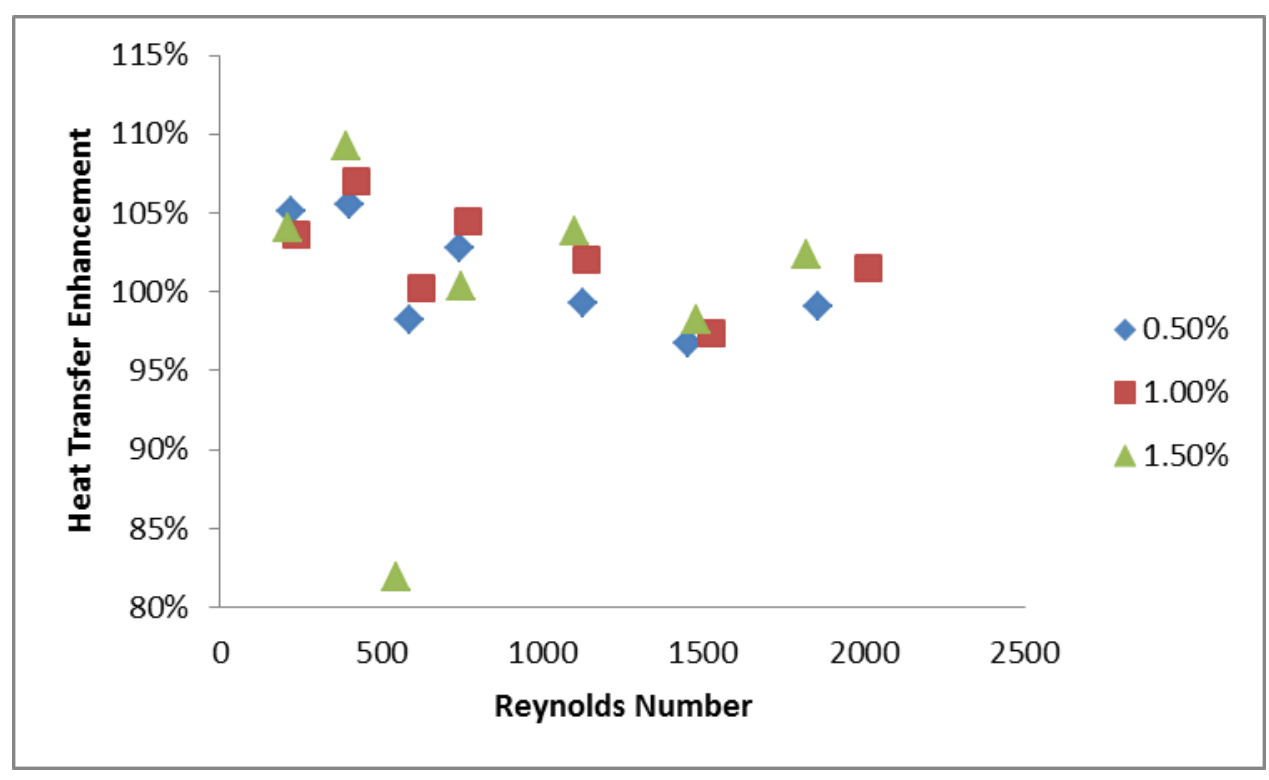

Figure 23 - Heat transfer enhancement of carbon coated cobalt nanofluids dispersed in PAO at different loading concentrations as a function of Reynolds Number at $65{ }^{\circ} \mathrm{C}$ 


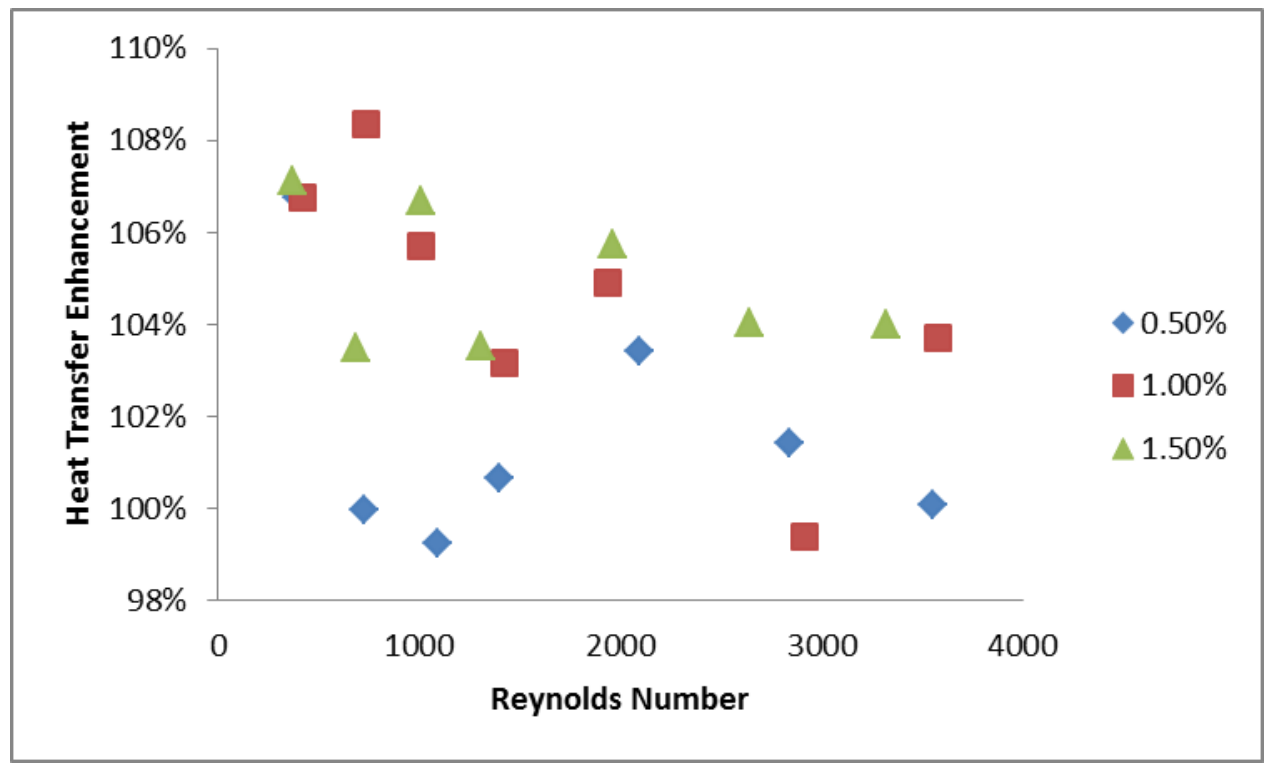

Figure 24 - Heat transfer enhancement of carbon coated cobalt nanofluids dispersed in PAO at different loading concentrations as a function of Reynolds Number at $90{ }^{\circ} \mathrm{C}$

\section{Effect of Particle Composition}

When comparing the heat transfer enhancements between the cobalt and the copper based nanoparticles, several differences are shown. These differences are discussed in more detail in later sections. When comparing the general overall enhancement numbers, over all of the testing variables, it is clear that the enhancement seen by the copper nanofluids is higher than that of the cobalt nanofluids. This difference in improvement can be explained due to the differences in the thermal conductivities of the two metals. Copper has a thermal conductivity of $401 \mathrm{~W} / \mathrm{m}-\mathrm{K}$ where cobalt has a thermal conductivity of only $100 \mathrm{~W} / \mathrm{m}-\mathrm{K}$. This trend of the higher thermal conductivity of a nanoparticle leading to a higher heat transfer enhancement has been observed many times, the most common 
of cases is when comparing the enhancement of a pure metal to its less conducive oxidized form. [11]

\section{Effect of Reynolds Number}

Analysis of the heat transfer enhancement with respect to Reynolds Number is performed to understand the effect of modifying the flow rate of the fluid. The reason the Reynolds Number is used as opposed to simply looking at the change in the flow rate is due to the fact that Reynolds Number is a more robust measurement in relation to flow patterns. The main variable that makes this measurement more ideal in this analysis is the effect of viscosity on the flow pattern. When dealing with nanofluids a change in viscosity is observed, as mentioned earlier.

The Reynolds Number separates flow patterns into three distinct groups. For smooth pipes a Reynolds Number of $0-2100$ correlates a fluid that is in the laminar flow regime. The laminar flow regime is characterized by a fluid flowing in the pipe with no radial mixing and with a gradual velocity distribution between the center of the pipe and the wall of the pipe. Any flowing fluid with a Reynolds Number above 4000 is considered to be in the turbulent flow regime. In this flow regime there is extensive mixing of the fluid in the radial direction caused by eddies in the fluid and represents a more chaotic flow. In this regime there is no distinct velocity distribution. If the fluid has a Reynolds Number of $2100-4000$ the fluid is considered as being in the transition flow regime. In this regime there are fluid flow patterns of both laminar and turbulent flow. 
In this experiment Reynolds Numbers in the range of 100 - 3800 were calculated over all the testing points. This means that testing was only able to be done on fluids in the laminar or transition flow regime. When comparing heat transfer enhancements inside each flow regime there was no discernable dependence on Reynolds Number. There was also no dependence on which flow regime the fluid was in. This observation means that the nanoparticles lead to a constant enhancement of the heat transfer coefficient, regardless of Reynolds number as long as the fluid is in the laminar or transition flow regime. It is important to note however that only 12 data points were able to be collected for the transition flow regime, as opposed to the 114 data points in the laminar flow regime.

\section{Effect of Fluid Temperature}

For this experiment three different temperatures were chosen to analyze heat transfer enhancement; these temperatures were 50,65 , and $90{ }^{\circ} \mathrm{C}$. These temperatures were controlled by passing the fluid through several meters of tubing that was submerged in a programmable water bath prior to entering the heat transfer section. There tends to be two different trends for the heat transfer enhancement depending on the nanoparticle material. For the copper based nanofluid as the temperature increases the heat transfer enhancement decreases. However, for the cobalt based nanofluids the opposite trend is observed; as the temperature of the fluid increases the heat transfer enhancement also increases. 
When trying to understand the general heat transfer enhancement of nanofluids, there are four proposed mechanisms behind the enhancement. These mechanisms, proposed by Eastman et al., are molecular level layers, aggregation, heat transfer properties of the nanoparticles, and Brownian motion of the particles. [13] When a temperature change is induced in the system there are two of these mechanisms that are likely to change. The first is the molecular level layering of the fluid on the particles. As the temperature of the fluid increases, there is an increase in kinetic energy in the fluid. This increase in kinetic energy leads to a decrease in the ability of the base fluid to create evenly distributed layers on the surface of the nanoparticles. The second mechanism that changes is the Brownian motion of the nanoparticles. When the temperature of the fluid increases, the viscosity of the base fluid decreases. With a lower viscosity there is a reduced resistance to movement of the particles, thus increasing their Brownian motion.

When dealing with fluid flows in the laminar regime there are two other mechanisms that could cause a decrease in the heat transfer enhancements, as reported by Wu et. al. [14] The first of these is the rapid alignment of nanoparticle in low viscosity fluids. This results in less particle/particle contact and decreases the ability for heat to propagate through the fluid. The second mechanism is a depletion of particles in the near-wall fluid phase. This leads to a lower thermal conductivity of the fluid in contact with the wall, where the temperature gradient is the largest. It is not obvious exactly which of these mechanisms is dominating in this system. However, it appears that the copper nanoparticles exhibit different properties than the cobalt nanoparticles, resulting in a different dominant heat transfer mechanism. 


\section{Effect of Particle Concentration}

The last major experimental testing variable that was changed was the effect of changing the concentration of nanoparticles in the fluid. For this experiment three different mass concentrations were tested for both nanoparticle dispersions, $0.5,1.0,1.5 \mathrm{wt} \%$. In general as the concentration of the nanoparticles increases, the heat transfer enhancement of the fluid also increases. This trend makes sense based on the fact that adding more particles of a higher thermal conductivity than the base fluid would increase the heat transfer coefficient. This trend has been reported by Pak and Cho in a system consisting of $\gamma-\mathrm{Al}_{2} \mathrm{O}_{3}$. [15]

The only time that this trend didn't hold was in the copper based nanofluid at the highest concentration of $1.5 \mathrm{wt} \%$. In this instance a relatively large decrease in heat transfer enhancement is observed over all fluid temperatures when compared to the $1.0 \mathrm{wt} \%$. A potential explanation for this drop in enhancement can be due to a buildup of nanoparticles on the wall of the heat transfer section. Cleaning of the heat transfer rig was only conducted when the nanofluid was changed from copper based to cobalt based. This allows for a large period of time for nanoparticles to adhere to the wall of the heat transfer section and inhibit the heat transfer into the system. During the cleaning process several system flushes with kerosene were required in order to remove the residual nanoparticles left in the system, supporting this theory of nanoparticle buildup. 


\section{CONCLUSIONS}

There were two primary objectives present in this research. The first was to create stable oil based nanofluids utilizing carbon shell and metal core nanoparticles. The metal cores used in this research were copper and cobalt. The second objective was to analyze how the different cores of the nanoparticles would influence the heat transfer enhancement of the fluid.

Several different testing variables and system parameters were altered to analyze the heat transfer enhancement. Three different particle concentrations were used $(0.5 \mathrm{wt} \%, 1.0$ $\mathrm{wt} \%$, and $1.5 \mathrm{wt} \%$ ) to analyze these enhancements. For each fluid three different fluid temperatures $\left(50,65,90^{\circ} \mathrm{C}\right)$ were used to understand the impact of increasing kinetic energy in the system. The final system variable that was manipulated was the fluid flow rate into the system. Seven different flow rates ranging from $10-100 \mathrm{~mL} / \mathrm{s}$ we used to understand how a change in Reynolds Number effects the Enhancement.

The nanofluids were prepared using a Fisher Scientific Ultrasonic Dismembrator. Prior to preparing large scale batches of the nanofluids, smaller batches were sonicated and inspected for sedimentation. For the cobalt nanoparticles a stable suspension was achieved for 72 hours before noticeable sedimentation occurred. For the copper nanoparticles a stable suspension was achieved for 3 weeks without any noticeable sedimentation. 
The viscosities of the tested fluids were measured using a Brookfield DV-II viscometer. The addition of nanoparticles caused the viscosity of the base fluid to increase. The magnitude of this enhancement increased as the concentration of nanoparticles increased.

The Heat capacities of all tested fluids were measured using a TA Instruments Q20 Differential Scanning Calorimeter. The copper based nanofluid showed a large increase in heat capacity at low particle concentrations, which started to drop back to that of the base fluid at $1.5 \mathrm{wt} \%$. The cobalt nanoparticles had a much smaller effect on the heat capacity. There was a minimal decrease in heat capacity at low concentrations, which started to rise above that of the base fluid at $1.5 \mathrm{wt} \%$.

Heat transfer coefficients of the fluids were calculated using a constant heat flux heat transfer rig. After an analysis of the heat transfer enhancement it was found that the Reynolds Number of the fluid had little to no impact on the enhancement. The nanoparticle composition played an important factor that caused the enhancement of the copper particles to be larger on average than the cobalt particles. This difference in enhancement is attributed to the much larger thermal conductivity of copper compared to cobalt. The particle composition also determined the effect that fluid temperature had on the enhancement. For the copper particles, as temperature increased the heat transfer enhancement decreased. However, for the cobalt particles as the temperature increased the heat transfer enhancement increased. It is hypothesized that this difference is due to a differing dominant enhancement mechanisms between the two particles. The final variable that was analyzed was how increasing the concentration of nanoparticles in the fluid impacted enhancement. For both fluids an increase in particle concentration led to 
an increase in heat transfer enhancement. For the $1.5 \mathrm{wt} \%$ of copper nanoparticles a drop in enhancement was observed, but it is thought to be caused by a buildup of nanoparticles on the wall of the heat transfer section. It is important to mention again that the volume concentrations being used in this research is approximately one order of magnitude lower than the majority of data published for nanofluids. 


\section{RECOMMENDATIONS}

1) Calculate the thermal conductivity of both nanofluids and see if the trends of the heat transfer enhancement are the same as the trends in the thermal conductivity improvements.

2) Attempt to manipulate the magnetic properties of the cobalt nanoparticles and determine its effect on the heat transfer enhancement.

3) Create nanofluids of cobalt nanoparticles without the carbon coating and compare heat transfer enhancements of the coated and uncoated nanoparticles.

4) Collect more data points for fluids in the transition flow regime to see if flow pattern impacts heat transfer enhancement.

5) Complete computational fluid dynamics modeling of the heat transfer system. This will allow for better understanding of the flow patterns in the system to help determine the mechanisms responsible for heat transfer enhancement.

6) Continue measurements on nanofluids used in this paper. Only one replicant was able to be measured due to time/material constraints. 


\section{REFERENCES CITED}

[1] S. Choi and J. Eastman, "Enhancing Thermal Conductivity of Fluids with Nanoparticles," in ASME International Mechanical Engineering Congress \& Exposition, San Francisco, 1995.

[2] J. C. Maxwell, A Treatise on Electricity and Magnetism, Clarendon Press, 1873.

[3] Y. Xuan and Q. Li, "Heat transfer enhancement of nanofluids," International Journal of Heat and Fluid Flow, vol. 21, no. 1, pp. 58-64, 2000.

[4] X.F.Li, "Thermal conductivity enhancement dependent $\mathrm{pH}$ and chemical surfactant for $\mathrm{Cu}$ H2O nanofluids," Thermochimica Acta, vol. 469, no. 1-2, pp. 98-103, 2008.

[5] R. S. Ruoff and S. Subramoney, "Single Crystal Metals Encapsulated in Carbon Nanoparticles," Science, vol. 259, pp. 346-348, 1993.

[6] Y. R. Uhm and S.-H. Jun, "Morphologies and dispersion stabilities of carbon encapsulated metal ( $\mathrm{Ag}$ and $\mathrm{Cu}$ ) nanoparticles synthesized by pulsed-wire evaporation (PWE)," Research on Chemical Intermediates, vol. 39, no. 7, pp. 3387-3398, 2013.

[7] J. Eastman and I. J. Thompson, "Anomalously increased effective thermal conductivities of ethylene glycol-based nanofluids containing copper nanoparticles," Applied Physics Letters, vol. 78, pp. 718-720, 2001.

[8] M.-S. Liu and C.-C. Wang, "Enhancement of thermal conductivity with Cu for nanofluids using chemical reduction method," International Journal of Heat and Mass Transfer, vol. 49, pp. 3028-3033, 2006.

[9] Y. Hwang and S. H. Kim, "Production and dispersion stability of nanoparticles in nanofluids," Powder Technology, vol. 186, pp. 148-153, 2008.

[10] K. Liu, Measurement of Heat Transfer Mechanisms in Oil-Based Nanofluids, University of Louisville, 2010.

[11] M. Rucker, Analysis of parameter impacting the heat transfer coefficient in oil-based nanofluids, University of Louisville, 2011.

[12] R. Prasher and P. Phelan, "Measurements of nanofluid viscosity and its implications for thermal applications," Applied Physics Letters, p. 89, 2006. 
[13] S. Choi and J. Eastman, "Mechanism of heat flow in suspensions of nano-sized particles (nanofluids)," Internation Journal of Heat and Mass Transfer, vol. 45, pp. 855-863, 2002.

[14] Y. Yang and G. Wu, "Heat transfer properties of nanoparticle-in-fluid dispersions (nanofluids) in laminar flow," Internation Journal of Heat and Mass Transfer, vol. 48, pp. 1107-1116, 2005.

[15] B. C. Pak and Y. I. Cho, "Hydrodynamic and Heat Transfer Study of Dispersed Fluids With Submicron Metallic Oxide Particles," Experimental Heat Transfer, vol. 11, pp. 151-170, 1998. 


\section{APPENDIX}

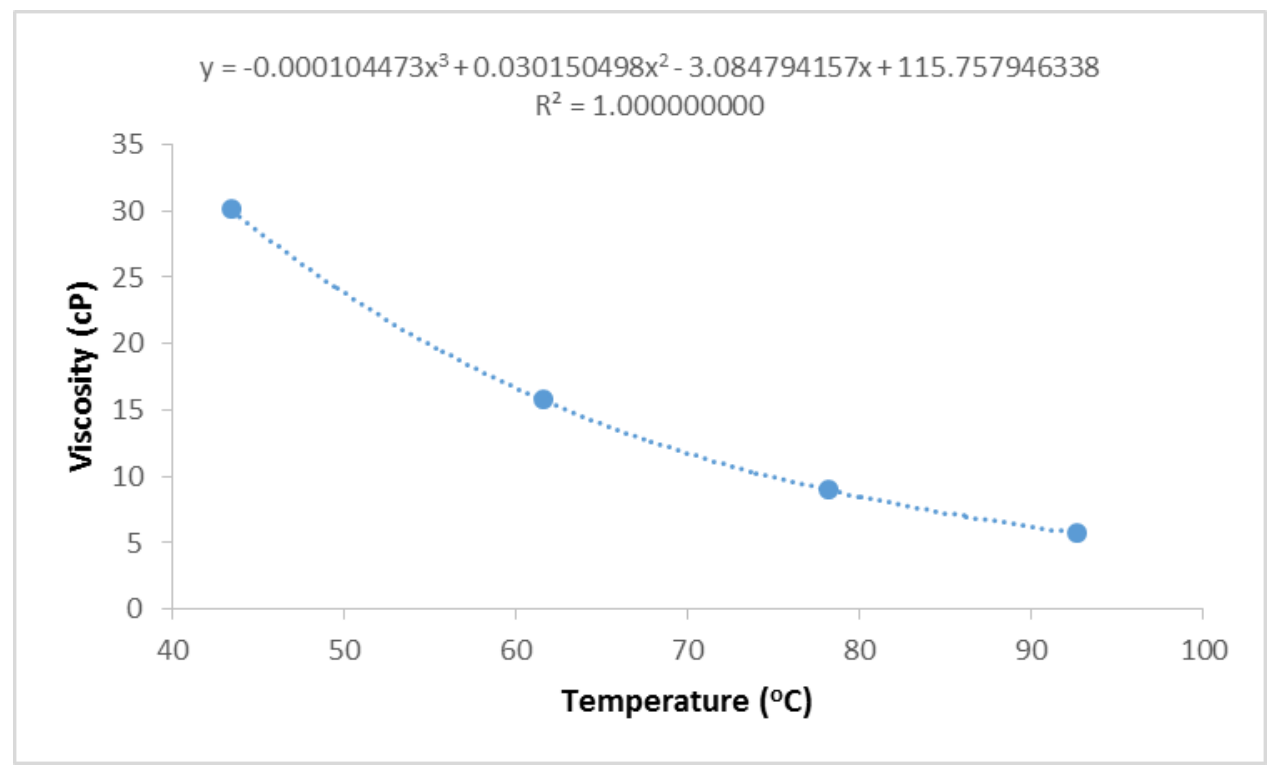

Figure 25 - Viscosity of PAO used as base fluid for carbon coated cobalt nanofluid dispersions as a function of temperature

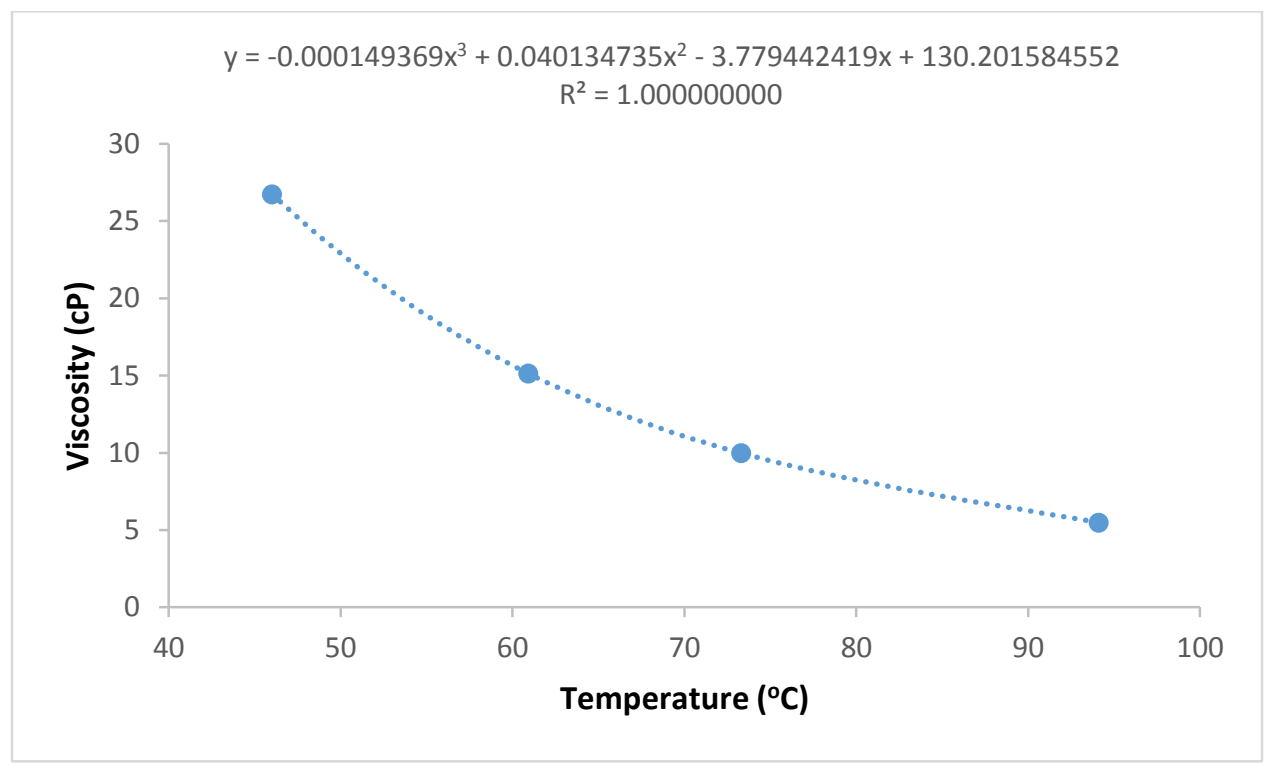

Figure 26 - Viscosity of carbon coated cobalt nanofluid dispersed in PAO base fluid at a loading concentration of $1.0 \mathrm{wt} \%$ as a function of temperature 


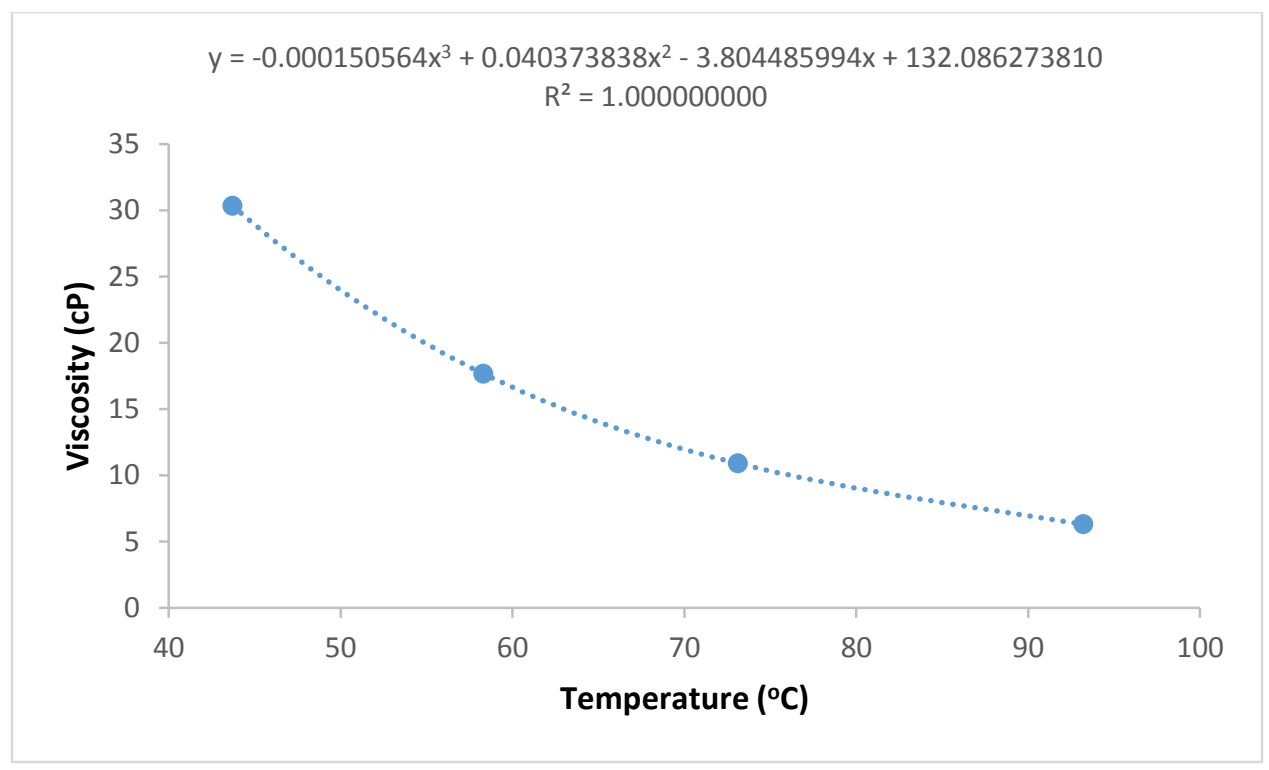

Figure 27 - Viscosity of carbon coated cobalt nanofluid dispersed in PAO base fluid at a loading concentration of $1.5 \mathrm{wt} \%$ as a function of temperature

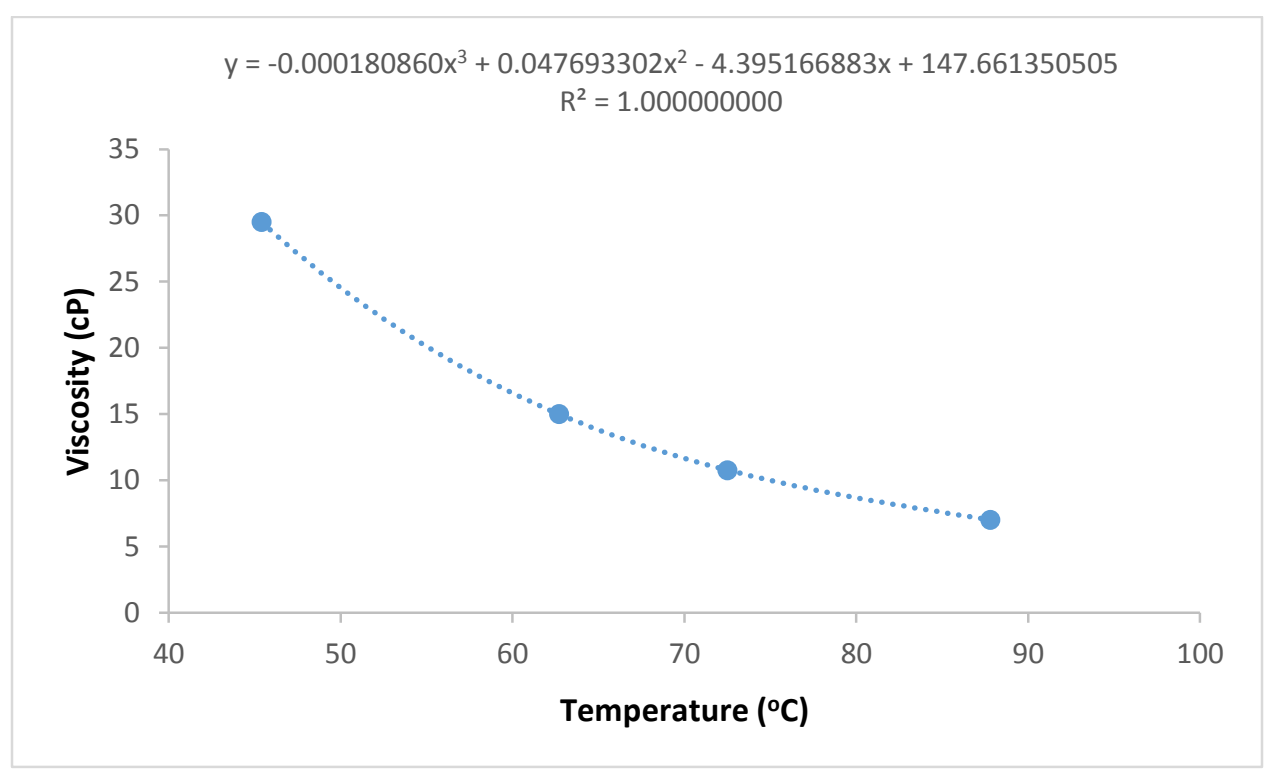

Figure 28 - Viscosity of PAO used as base fluid for carbon coated copper nanofluid dispersions as a function of temperature 


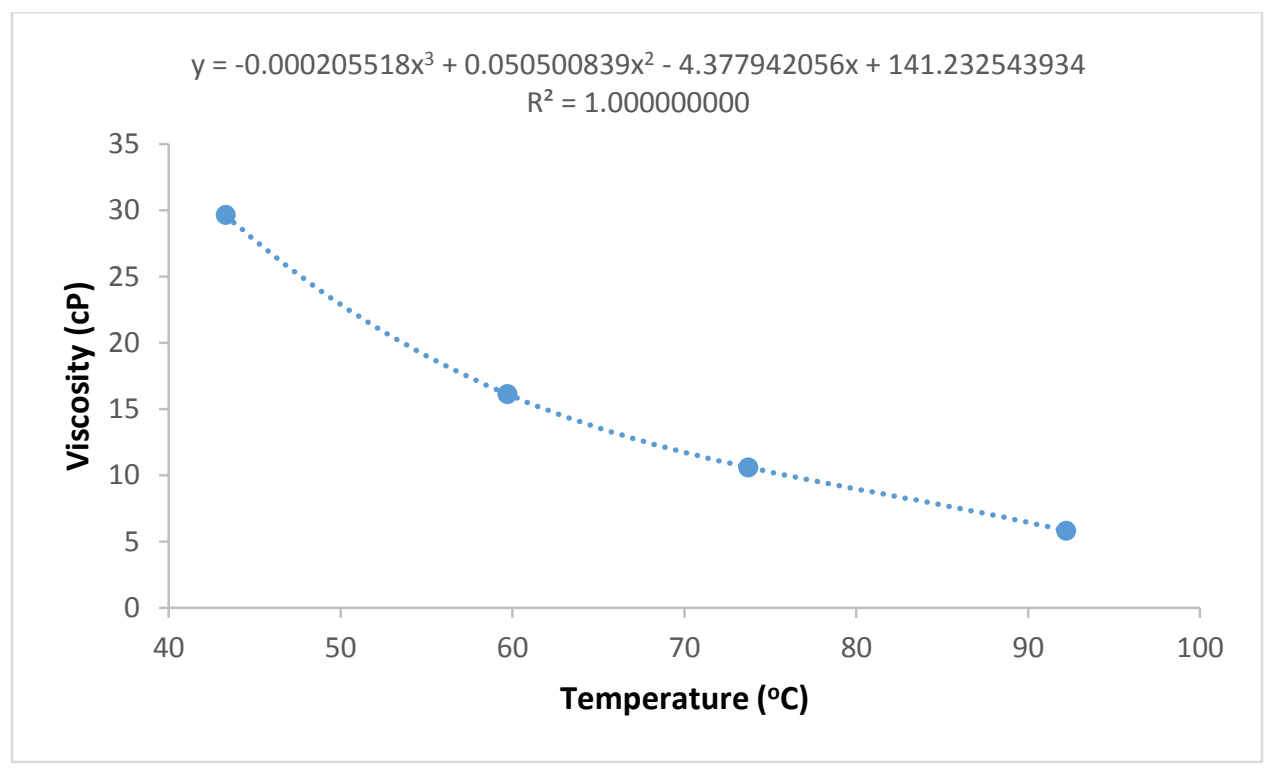

Figure 29 - Viscosity of carbon coated copper nanofluid dispersed in PAO base fluid at a loading concentration of $0.5 \mathrm{wt} \%$ as a function of temperature

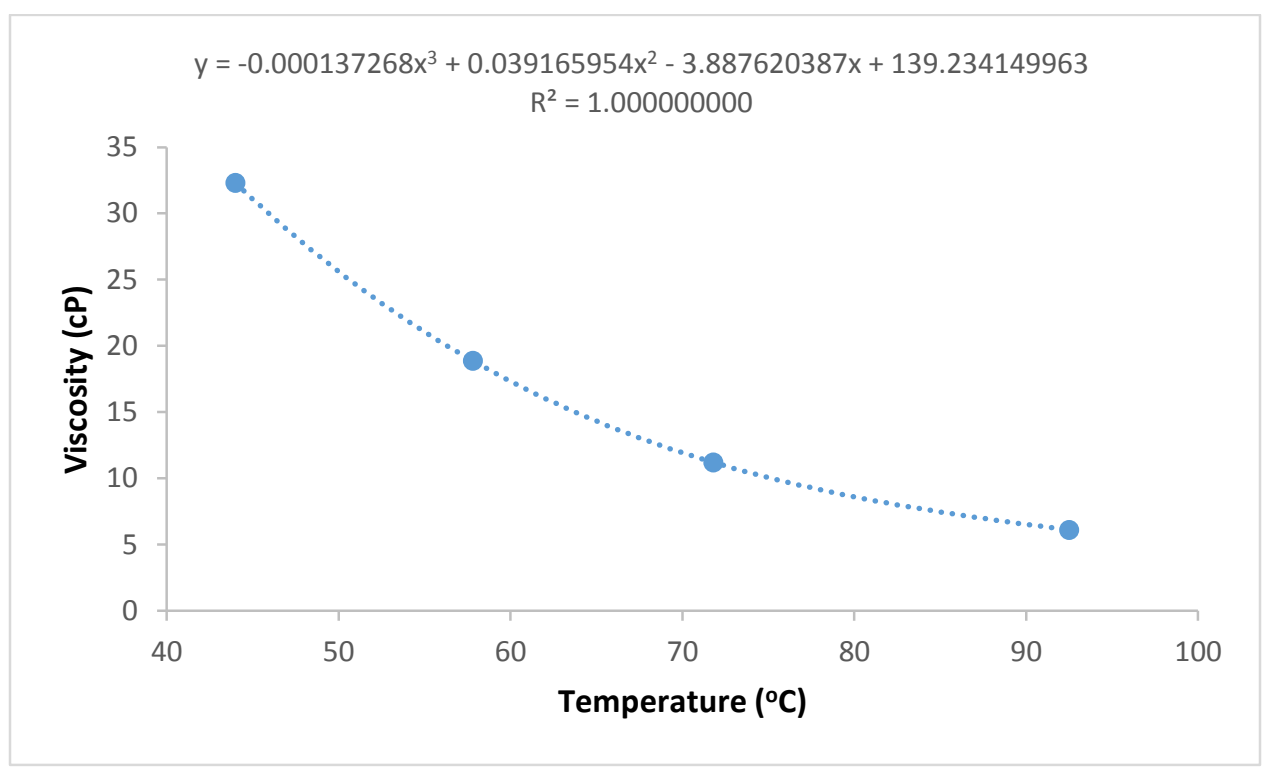

Figure 30 - Viscosity of carbon coated copper nanofluid dispersed in PAO base fluid at a loading concentration of $1.0 \mathrm{wt} \%$ as a function of temperature 


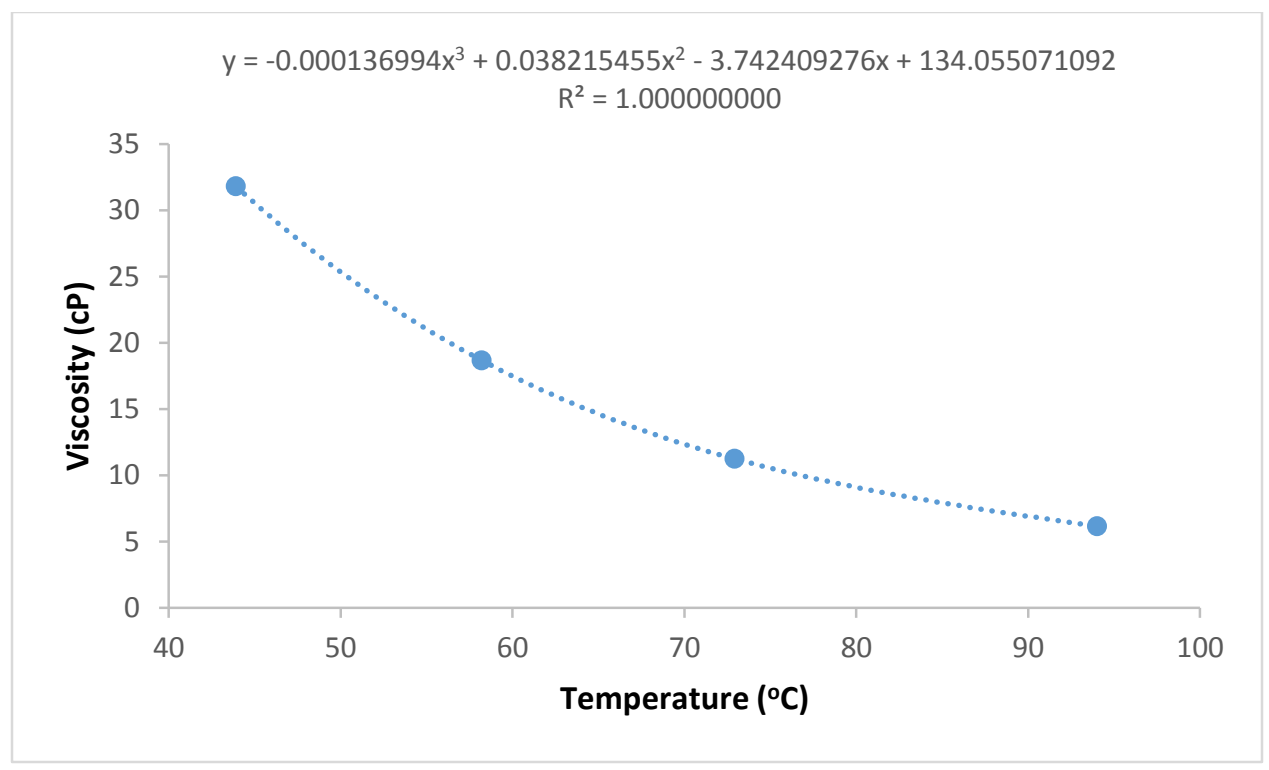

Figure 31 - Viscosity of carbon coated copper nanofluid dispersed in PAO base fluid at a loading concentration of $1.5 \mathrm{wt} \%$ as a function of temperature

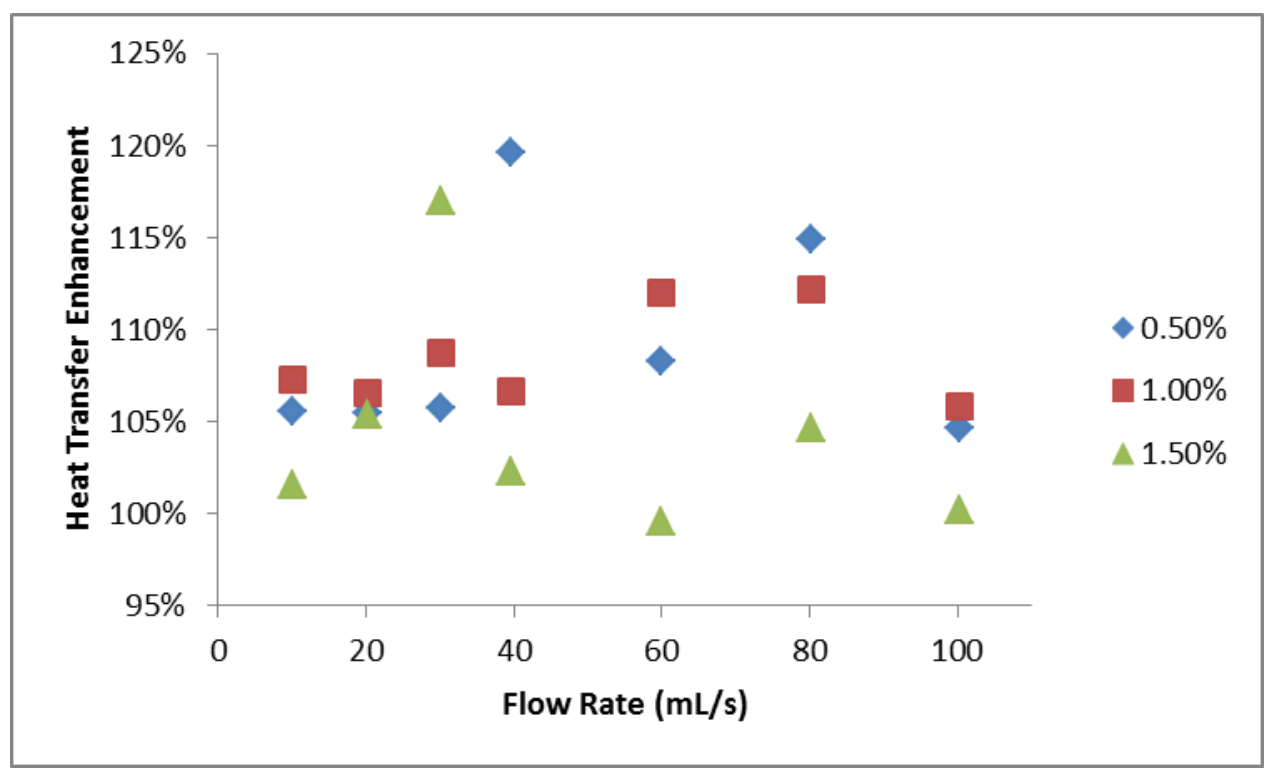

Figure 32 - Heat transfer enhancement of carbon coated copper nanofluids dispersed in PAO at different loading concentrations as a function of Flow Rate at $50{ }^{\circ} \mathrm{C}$ 


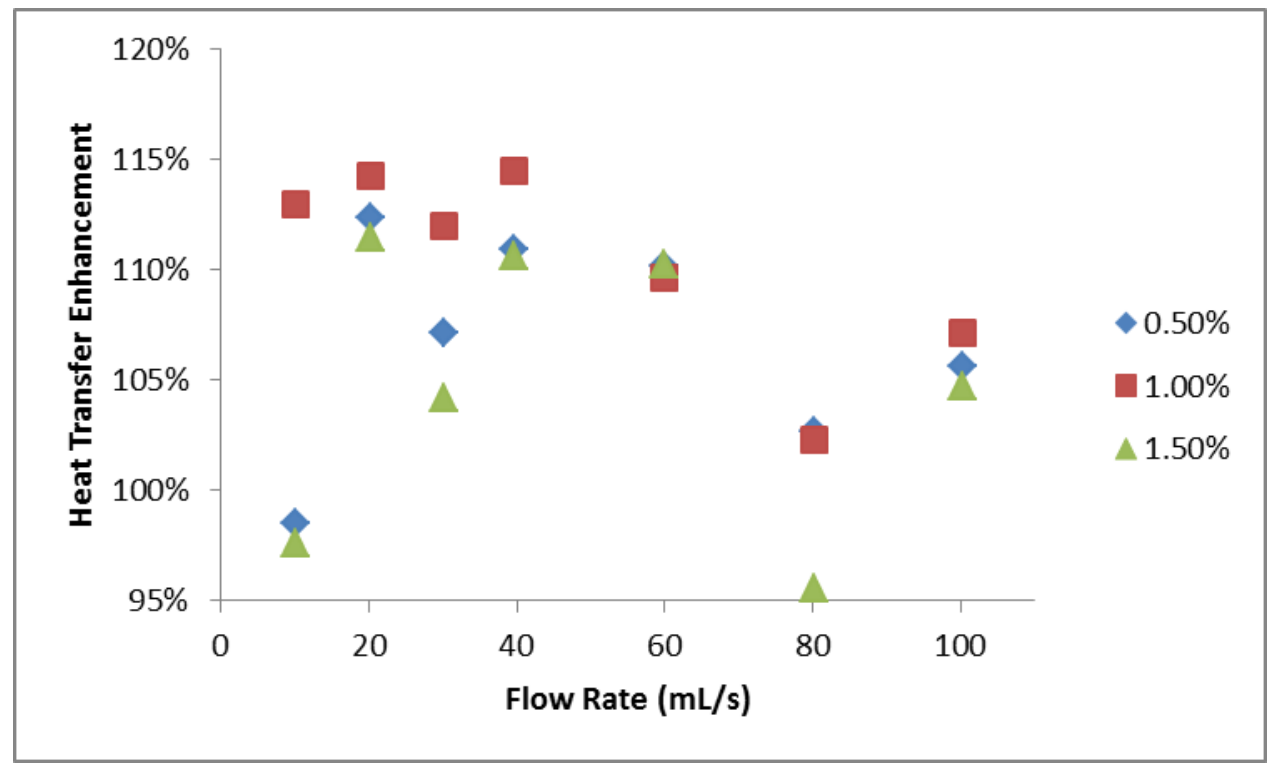

Figure 33 - Heat transfer enhancement of carbon coated copper nanofluids dispersed in PAO at different loading concentrations as a function of Flow Rate at $65{ }^{\circ} \mathrm{C}$

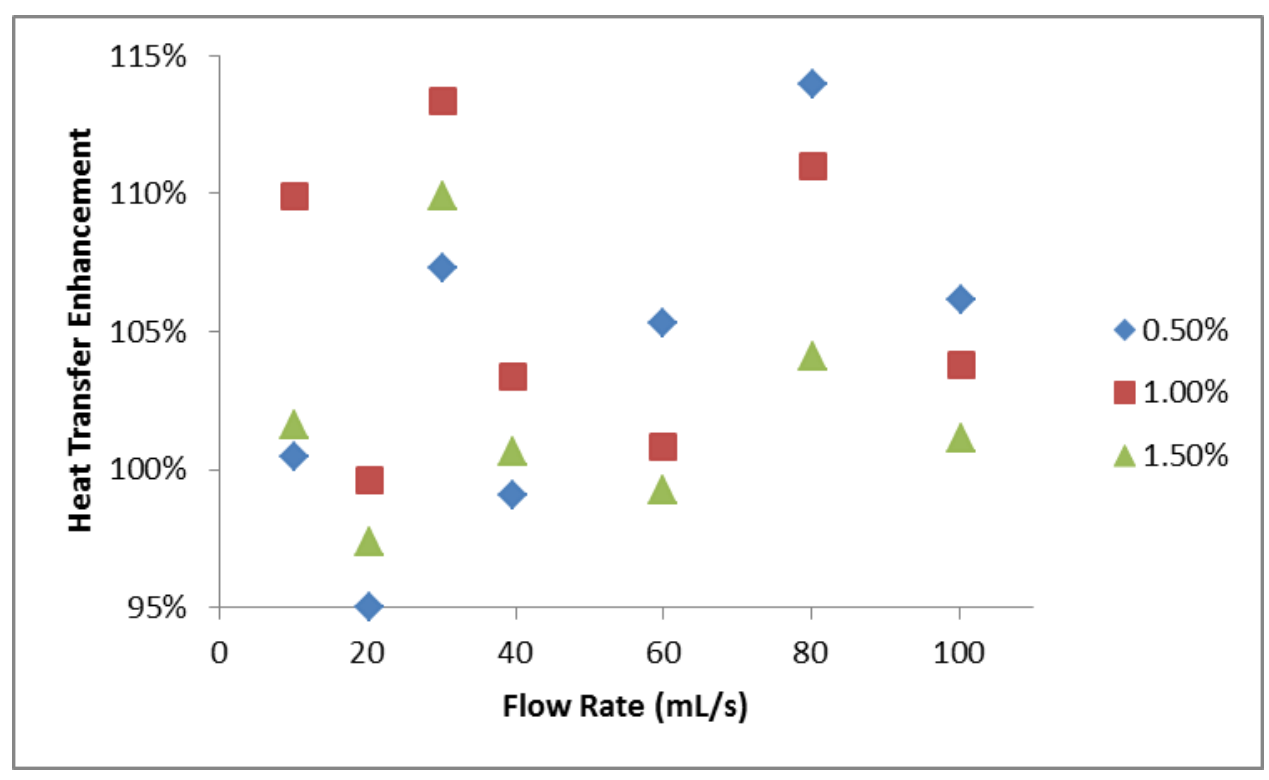

Figure 34 - Heat transfer enhancement of carbon coated copper nanofluids dispersed in PAO at different loading concentrations as a function of Flow Rate at $90{ }^{\circ} \mathrm{C}$ 


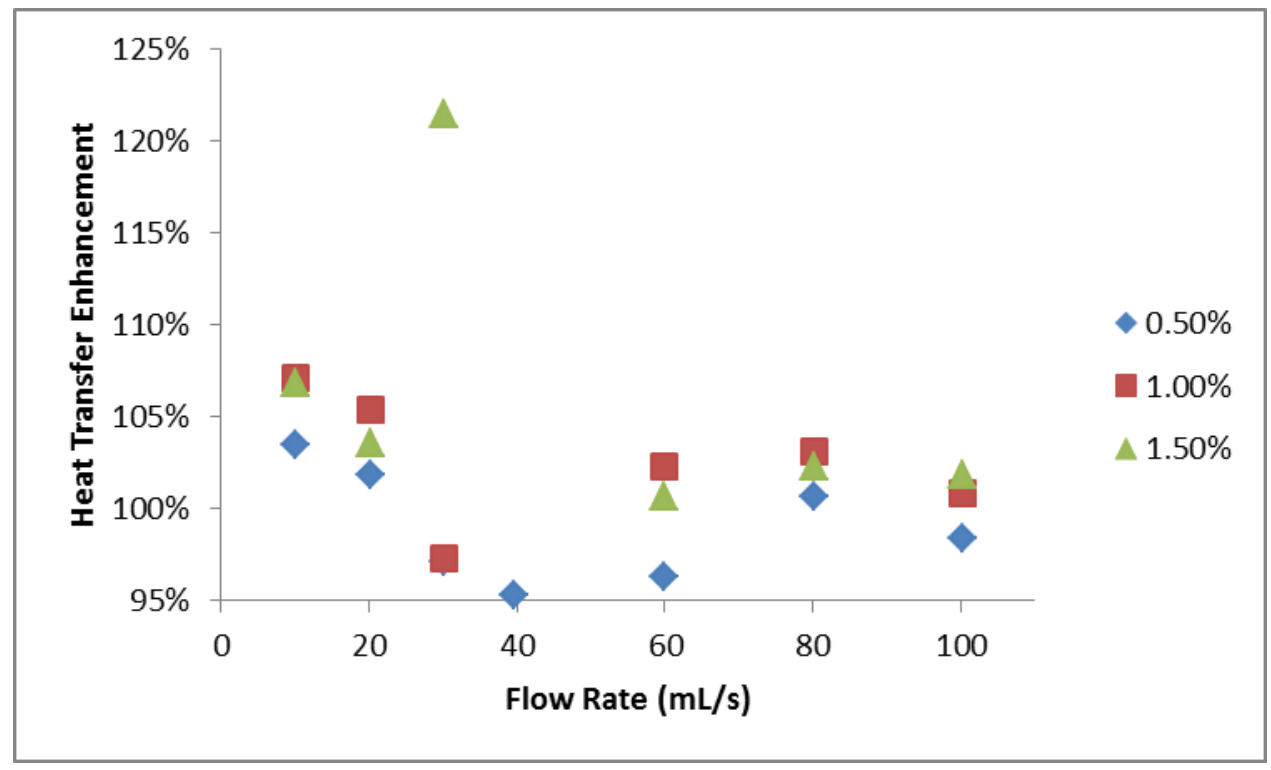

Figure 35 - Heat transfer enhancement of carbon coated cobalt nanofluids dispersed in PAO at different loading concentrations as a function of Flow Rate at $50{ }^{\circ} \mathrm{C}$

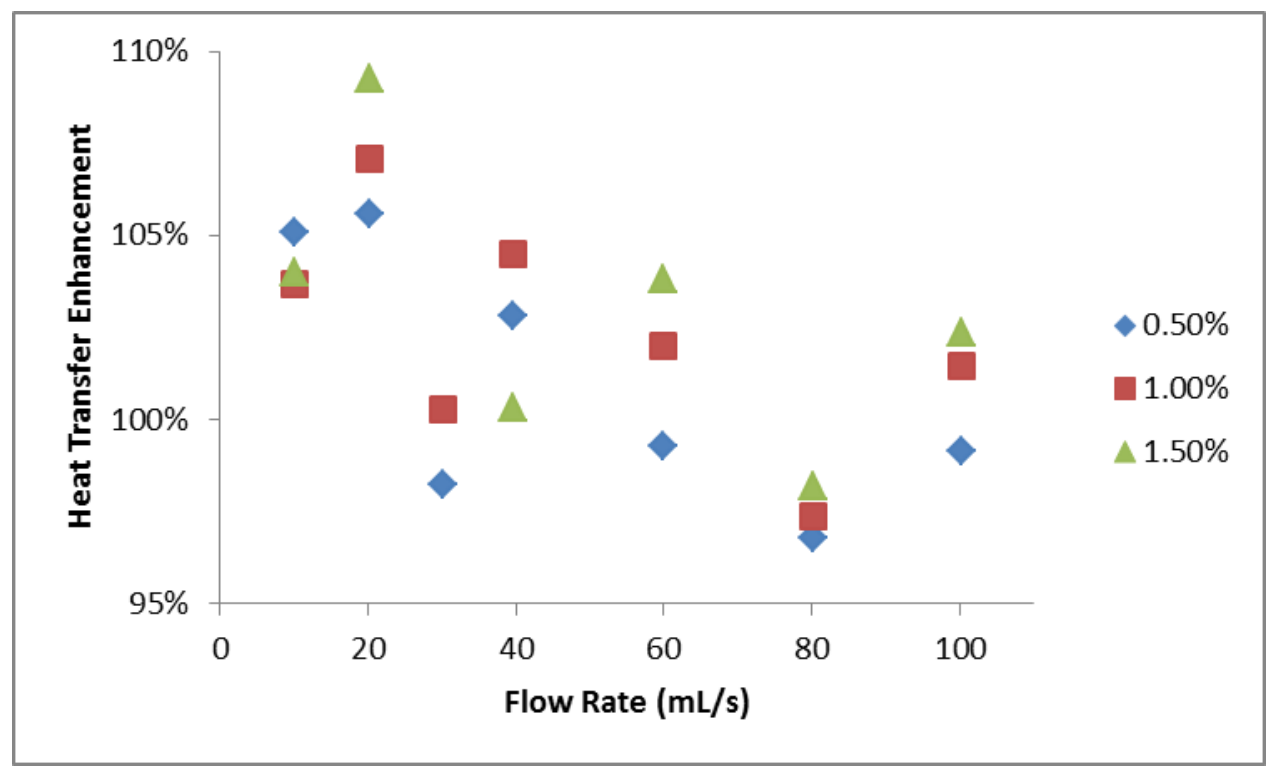

Figure 36 - Heat transfer enhancement of carbon coated cobalt nanofluids dispersed in PAO at different loading concentrations as a function of Flow Rate at $65^{\circ} \mathrm{C}$ 


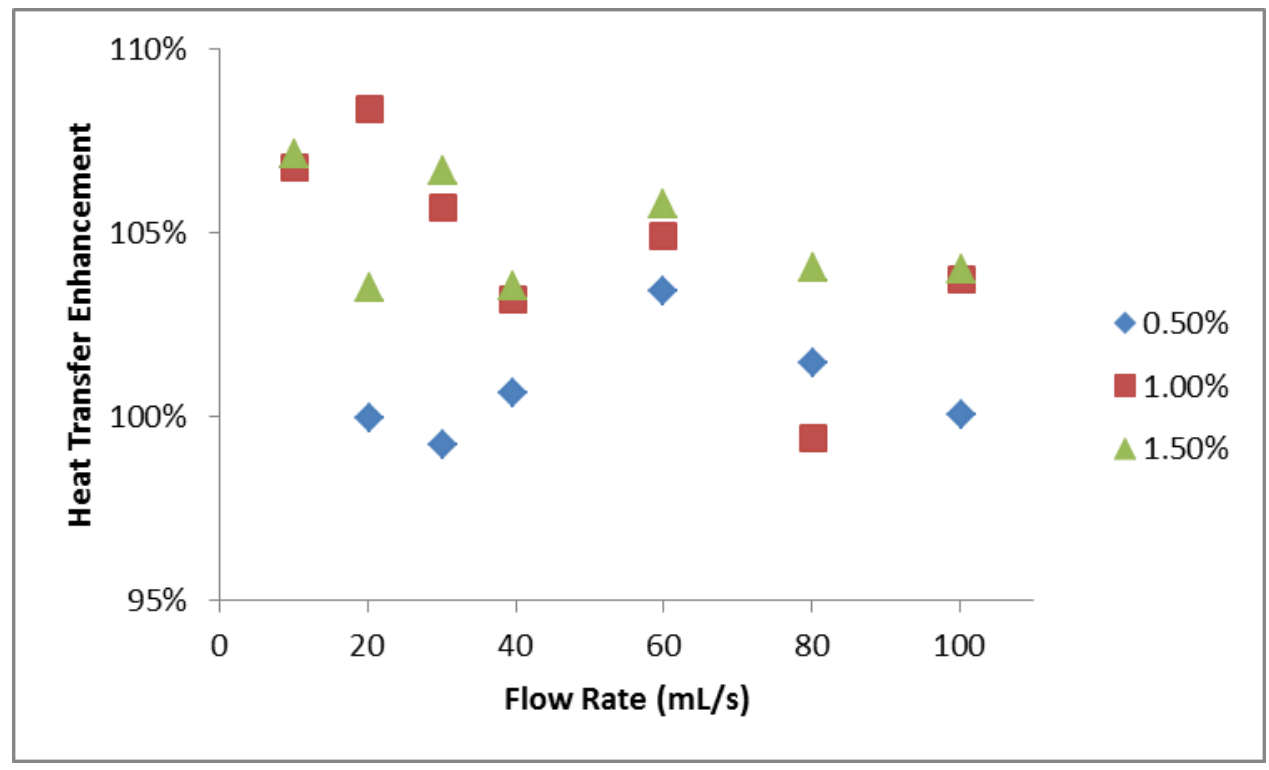

Figure 37 - Heat transfer enhancement of carbon coated cobalt nanofluids dispersed in PAO at different loading concentrations as a function of Flow Rate at $90{ }^{\circ} \mathrm{C}$ 
NAME: Cory Milligan

ADDRESS: Department of Chemical Engineering

University of Louisville

Louisville, KY 40292

EDUCATION: $\quad$ B.S., Chemical Engineering

University of Louisville

2009-2014

\section{WORKING}

EXPERIENCE: $\quad$ Chemical Engineering Co-op

SABIC Innovative Plastics

$2011-2012$

Undergraduate Teaching Assistant

University of Louisville

2012-2013 